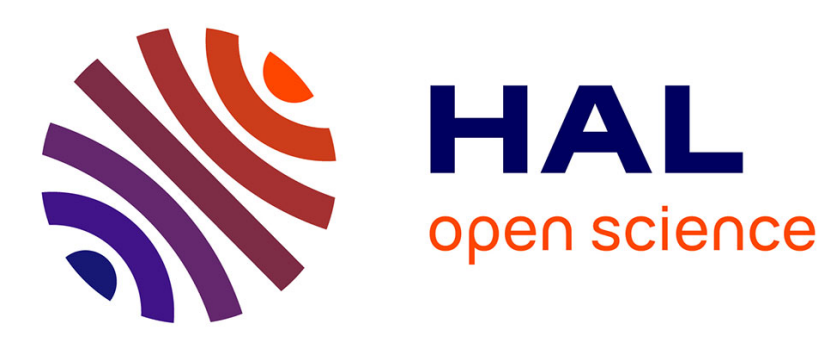

\title{
Blockchain Technology and Financial Regulation: A Risk-Based Approach to the Regulation of ICOs
}

\author{
Alexis Collomb, Primavera de Filippi, Klara Sok
}

\section{To cite this version:}

Alexis Collomb, Primavera de Filippi, Klara Sok. Blockchain Technology and Financial Regulation: A Risk-Based Approach to the Regulation of ICOs. European Journal of Risk Regulation, 2019, 10.1017/err.2019.41 . hal-02445195

\section{HAL Id: hal-02445195 \\ https://hal.science/hal-02445195}

Submitted on 20 Jan 2020

HAL is a multi-disciplinary open access archive for the deposit and dissemination of scientific research documents, whether they are published or not. The documents may come from teaching and research institutions in France or abroad, or from public or private research centers.
L'archive ouverte pluridisciplinaire $\mathbf{H A L}$, est destinée au dépôt et à la diffusion de documents scientifiques de niveau recherche, publiés ou non, émanant des établissements d'enseignement et de recherche français ou étrangers, des laboratoires publics ou privés. 


\title{
1 Blockchain Technology and Financial \\ 2 Regulation: A Risk-Based Approach to the \\ 3 Regulation of ICOs
}

4 Primavera DE FILIPPI ${ }^{\circledR}$, Alexis COLLOMB and Klara SOK

\begin{abstract}
This paper compares Initial Public Offerings (IPOs) and equity crowdfunding with Initial Coin Offerings (ICOs) and explores the corresponding risks and limitations of these different fundraising practices, with a view to analysing the extent to which the latter should be subject to the same regulatory framework as the former. After assessing the underlying principles and current regulatory framework for IPOs and equity crowdfunding, with a focus on Europe and the US, we investigate the possibility of applying existing financial regulations to ICOs. Drawing from the notion of "functional equivalence", we contend that many ICOs share a sufficient number of similarities with traditional IPOs and equity crowdfunding, to be regulated in a similar manner. However, given the various attempts by token issuers to escape from the scope of securities laws by assigning a different function to their ICOs tokens, we argue that principle-based regulation based on an in-depth riskanalysis could be an effective way of addressing the regulation of ICOs, thereby moving from "functional equivalence" to "risk equivalence". Finally, we explore the use of blockchain technology as a regulatory technology, incorporating specific rules and constraints into the technological fabric of an ICO, in order to ensure compliance with the fundamental principles of financial regulation.
\end{abstract}

New fundraising techniques have emerged in the last few years, with the advent of blockchain technology. An Initial Coin Offering (ICO) - also referred to as a "token sale" or "token generating event" - can be loosely described as a new fundraising technique, whereby blockchain-based tokens are sold in exchange for cryptocurrencies (or fiat money) with a view to supporting the development of a particular project or initiative. Different functions can be assigned to these tokens: they can be used as a means to access a particular product or service (utility tokens), as a proxy to another physical or digital asset (asset-backed tokens), as a digital representation of an equity share or a stock (investment tokens), or even as a right of governance into the project or initiative being funded (governance tokens). Moreover, regardless of the function ascribed to the ICO tokens, most of the actors purchasing 
these tokens are also interested in the potential gains that can be derived from the sale of these tokens on a secondary market.

The first token sale was done by Mastercoin in July 2013, followed in 2014 by Ethereum and a few other token sales. ICOs started to pick up with TheDAO's token sale in May 2016, which raised circa US $\$ 150 \mathrm{~m}$. But it was only in 2017 that significant volumes were achieved. By the end of 2018, ICOs had cumulatively raised about US $\$ 24$ billion through more than 5,000 token sales ${ }^{1}$ and, despite various regulatory headwinds, the pace and volume of these offerings kept growing until March 2018 - with a peak of circa $\$ 1.8$ billion raised during that month alone.

This paper will first provide an overview of financial regulations related to IPOs and equity crowdfunding, both in Europe and in the US It will then describe the ICO process, delineating the various steps that characterises an ICO - prior, during, and after the contribution period. The paper will then analyse the specificities of ICOs, and the extent to which they can be assimilated to more ordinary fundraising practices. While, from the perspective of a formal analysis, ICOs differ significantly from traditional IPOs, from a functional analysis, there are nonetheless important similarities between the two. The paper will investigate whether these similarities could justify bringing these new fundraising practices within the scope of existing regulatory frameworks for security offerings, or whether - in light of their distinctive characteristics - ICOs might benefit from a different set of regulations.

Many actors experimenting with ICOs have been trying to find ways to prevent their tokens from being characterised as securities, thereby bypassing the need to comply with securities regulations. Yet, by comparing the risks involved in IPOs, equity crowdfunding, and ICOs, it becomes immediately clear why the latter might be subject to similar regulatory constraints as the more traditional fundraising practices. Indeed, although they differ in their format and design, all ultimately fulfil the same function: they all represent a means of raising public funds for the development of a particular project or initiative, with a certain degree of risk for investors with regard to their potential return on investment.

This paper claims that past and current attempts by token issuers at running afoul of security regulations by merely pretending that, because of its technical design or intended function, a token shall not be regarded as a security, ultimately illustrates an important misunderstanding of the role and purpose of securities regulations. Indeed, while securities laws are intended to facilitate capital formation within a fair, orderly and efficient market, one of their most prominent functions is also to protect investors against undue potential losses, and to make sure they clearly understand the financial risks they are taking. Hence, regardless of their legal qualification, the public issuance of blockchain-based tokens might constitute a regulated activity to the extent that it imposes a similar set of risks to investors.

This paper argues that, in order to establish whether an ICO should be regulated as a securities offering, one should not look at the legal qualification of the tokens being issued, but rather at the functions assumed by these tokens. Building upon the notion of functional equivalence - a legal doctrine used to extend existing regulations to

1 Sources: <w.coindesk.com/ico-tracker $>$ and $<$ icobench.com/reports/ICO_Market_Analysis_2018.pdf > . 
new products or practices which are formally distinct, and yet functionally equivalent to previous regulated products or activities - the paper analyses the extent to which existing financial regulations might apply to different types of ICOs. The paper then suggests a reinterpretation of the doctrine of functional equivalence, focusing not only on the function but also on the risks posed by these new fundraising practices. It provides a risk-based analysis to establish the extent to which the risks raised by an ICO are similar to those raised by traditional IPOs. If the risks of the two are sufficiently similar (both in degree and in kind), it is fair to contend that they should both be subject to a similar regulatory framework.

The paper concludes by providing a series of recommendations and best practices for token issuers, suggesting that instead of trying (in vain) to construct their ICOs so as to reduce the likelihood that their tokens will be regarded as a security, tokens issuers should rather focus on exploring the use of blockchain technology as a "regulatory technology"ie as means to decrease the risks for investors (eg by providing increased transparency, auditability and accountability) and consequently reduce the regulatory burden that issuers might be subjected to.

\section{EXISTING REGULATORY FRAMEWORK FOR "PUBLIC FUNDRAISING"}

\section{Policy objectives and underlying principles for the regulation of IPOs}

Capital markets regulation has the ambition to provide a clear, yet flexible framework with a multi-pronged objective of protecting issuers and investors from any potential fraud or abuse, while fostering economic growth. With regard to securities, the International Organization of Securities Commissions clearly summarises the three key objectives of securities regulation: ${ }^{2}$ (i) protecting investors; (ii) ensuring fair, efficient and transparent markets; and (iii) reducing systemic risk. The regulation of IPOs, whether in Europe or in the US, aims at fulfilling these three broad regulatory objectives.

The ordering of these objectives suggests that investor protection is the first concern of securities commissions. In fact, in the wake of the 2008 financial crisis, the need for investor protection has been recognised of utmost importance in a set of high-level principles on consumer protection in the field of financial services which was called for by the G20 Finance Ministers and Central Bank Governors in February 2011, ${ }^{3}$ and introduced in October of the same year. ${ }^{4}$

2 See p $3<$ www.iosco.org/library/pubdocs/pdf/IOSCOPD561.pdf>.

3 This set of high-level principles was developed by "the Task Force on Financial Consumer Protection of the OECD Committee on Financial Markets (CMF), in close co-operation with the FSB and its Consultative Group, other international organisations and standard setter bodies and consumer and industry associations": see <www.oecd. $\mathrm{org} / \mathrm{daf} / \mathrm{fin} /$ financial-markets/48892010.pdf $>$.

4 This set of common principles comprises ten sections respectively dealing with: (i) the legal, regulatory and supervisory framework; (ii) the role of oversight bodies; (iii) the equitable and fair treatment of consumers; (iv) disclosure and transparency; (v) financial education and awareness; (vi) responsible business conduct of financial services providers and authorised agents; (vii) protection of consumer assets against fraud and misuse; (viii) protection of consumer data and privacy; (ix) complaints handling and redress; and (x) competition. It is interesting to notice that this list of high-level principles combines moral objectives (eg the equitable and fair treatment of consumers) with more practical means to achieve consumer protection (eg financial education and awareness). 
The second objective underlines the economic importance of having efficient markets so that issuers can find investors to finance their operations, through a fair and transparent process. According to standard economic theories, one of the central market functions is to maximise economic welfare and economic surplus. ${ }^{5}$ One of the key issues that may hamper the good functioning of markets is information asymmetry. According to Akerlof's seminal paper on the market for "lemons", adverse selection ${ }^{6}$ may drive high-quality products out of the market, and potentially unravel it. ${ }^{7}$ Maximising economic surplus through an efficient market mechanism means that funds should find their way to an actual investment project every time it is mutually advantageous for the parties concerned. In a world without information asymmetries, this can be achieved via market mechanisms alone. However, markets are littered with uncertainty and information asymmetries. Insurance or financial market theorists, in the wake of Akerlof, have long been aware of the potentially destructive power of information asymmetries. Some market-based solutions have been suggested to mitigate the impact of information asymmetries and adverse-selection, with techniques such as signalling ${ }^{8}$, intermediation and third-party certification, or "buyer search" - whereby purchasers can acquire information on the true status of goods sold at a cost, by "visiting" a seller or testing the product for sale - as reviewed by Fox. ${ }^{9}$ In the context of an IPO, part of an underwriter's value, as an intermediary, is precisely to use its reputation to certify that the offering price reflects the issuer's insider information, which investors are not aware of, or simply cannot be sure of. ${ }^{10}$ However, as Fox shows, ${ }^{11}$ these methods are not perfect antidotes for eradicating the adverse effects of information asymmetries, especially when dealing with public offerings of securities that are not already traded in a secondary market. ${ }^{12}$

The last objective of reducing systemic risk has been emphasised ever since the 2008 subprime crisis "spilled over and became the catalyst for a much broader global financial crisis". 13

Stepping back, it can be observed that economic and financial history has been fraught with examples where one - or several - of the three aforementioned objectives were trampled upon. From the South Sea Company bubble of 1711-1720 to the great crash of 1929, and the crisis of 2008, there are many instances where investors have been

\footnotetext{
5 On this issue, see Just et al, The Welfare Economics of Public Policy (Edward Elgar 2004) chs 7-9.

6 A market with products of various qualities (eg high and low) will be said to experience adverse selection when sellers of high-quality products decide not partake in the market because buyers are unable to distinguish between highand low-quality products, and are hence unable to pay a high enough price for matching high-quality sellers' reservation price.

7 A Akerlof, “The market for 'lemons': quality uncertainty and the market mechanism” (1970) 84(3) The Quarterly Journal of Economics 488.

8 M Spence, "Competitive and optimal responses to signals: an analysis of efficiency and distribution" (1974) 7(3) Journal of Economic Theory 296.

9 MB Fox, "Regulating Public Offerings of Truly New Securities: First Principles" (2016) 66 Duke Law Journal 673.

10 Such an analysis of an underwriter's value can be found in.

11 Fox, supra, note 9.

12 Fox therefore argues that we should be going back to first principles to answer "whether, and, if so, under what circumstances, government regulation should be added to the mix", supra, note 9, p 677.

13 FA Longstaff, "The subprime credit crisis and contagion in financial markets" (2010) 97(3) Journal of Financial Economics 436 .
} 
ruined by collapsing share prices. Investor protection is a difficult goal as financial markets can go mad, and investors may be prone to irrational exuberance. Similarly, the fairness, efficiency and transparency of markets is another difficult objective to achieve, as markets can be manipulated by powerful actors. ${ }^{14}$ Lastly, the recent subprime crisis has shown that systemic risk can gradually build up and remain unnoticed until it is too late. Furthermore, these three goals are inherently correlated and it will be hard to achieve one without the others. For instance, an efficient control of systemic risk will require a certain level of transparency in the markets, just as investor protection will be hard to achieve if another systemic crisis were to unleash its devastating effects. We now turn to analysing the regulatory framework established in Europe and in the US to achieve the three objectives of securities law.

\section{a. European IPO regulatory regime}

In the aftermath of the 2008 financial crisis, European financial regulation was adjusted to improve the functioning of financial markets. Directive 2003/71/EC ${ }^{15}$ (the Prospectus Directive), which was the cornerstone of European IPO regulation, was repealed on 14 June 2017 and replaced by Regulation (EU) 2017/1129 ${ }^{16}$ (the Prospectus Regulation) in an effort to build a Capital Markets Union and "help businesses tap into more diverse sources of capital from anywhere within the European Union, make markets work more efficiently and offer investors and savers additional opportunities to put their money to work, in order to enhance growth and create jobs". ${ }^{17}$ If, overall, this new Regulation maintains the fundamental principles laid out in the 2003 Directive, it introduces certain technical modifications designed to strengthen investor protection and overall market efficiency, while introducing more flexibility for issuers. We can see a triple objective at work in this regulatory adjustment: (i) reinforcing investor protection; (ii) making markets more efficient, especially in the greater context of capital markets union; and (iii) introducing more flexibility to stimulate economic growth.

One of the important means to achieve the first key objective of protecting investors is to provide the latter with all essential information, in order to make sure that they properly understand the risks involved in their investments. The Prospectus Regulation gives the European Securities Markets Authority (ESMA) a mandate to develop guidelines to assist competent authorities - typically at the national level - in their review of the various risk factors that issuers will need to disclose. ${ }^{18}$ The ESMA guidelines require these risk factors to be specific, material, and presented across different categories

\footnotetext{
14 RJ Aggarwal and G Wu "Stock Market Manipulations" (2006) 79(4) The Journal of Business 1915.

15 Directive 2003/71/EC of the European Parliament and of the Council of 4 November 2003 on the prospectus to be published when securities are offered to the public or admitted to trading and amending Directive 2001/34/EC, available at <eur-lex.europa.eu/legal-content/EN/TXT/?uri=CELEX\%3A32003L0071>.

16 Regulation (EU) 2017/1129 of the European Parliament and of the Council of 14 June 2017 on the prospectus to be published when securities are offered to the public or admitted to trading on a regulated market, and repealing Directive 2003/71/EC, available at <eur-lex.europa.eu/legal-content/EN/TXT/?uri=CELEX:32017R1129>.

17 Introductory remark (1) of Prospectus Regulation.

18 Art 16(4) of Prospectus Regulation; ibid.
} 
depending on the nature of the risk. Quantitative - when possible - and qualitative information also needs to be provided for investors to properly assess potential risks. ${ }^{19}$

Yet, as pointed out by Hacker and Thomale, ${ }^{20}$ the Prospectus Regulation is not the only regulatory instrument concerned with the public offering of securities, or the dealing of financial instruments within Europe. The Market Abuse Regulation, ${ }^{21}$ which is focused on preventing various forms of insider trading and market manipulations, also applies to the trading of securities on trading facilities and regulated markets. Similarly, the Markets in Financial Instruments Directive (now in its second version, the MiFID II Directive ${ }^{22}$ ) seeks to improve the competitiveness of the EU's financial markets with a legislative framework intended to harmonise the degree of investors' protection in financial instruments. Among other things, the Directive sets out reporting requirements, transparency obligations for the trading of shares, as well as a series of rules on the admission of financial instruments. ${ }^{23}$ It also recognises that as "more investors have become active in the financial markets and are offered an even more complex and wide-ranging set of services and instruments", the European legal framework should encompass "the full range of investor-oriented activities" and "provide for the degree of harmonisation needed to offer investors a high level of protection". ${ }^{24}$ Again, this underlines how the key objective of protecting investors is pervasive across all these regulations. Furthermore, the idea that standardisation of financial instruments and investment vehicles will contribute to investor protection - helping investors and regulators alike better understand and manage investment risks by providing them with a unified framework across European markets - can also be found in the UCITS Directive, ${ }^{25}$ which oversees the cross-border operations throughout the EU of collective investment schemes; or its equivalent for alternative investment funds - the AIFM Directive. ${ }^{26}$ This wider set of European financial regulations ${ }^{27}$ has been

\footnotetext{
19 The final report on ESMA guidelines on risk factors under the Prospectus Regulation may be found at $<$ www. esma.europa.eu/document/final-report-esma-guidelines-risk-factors-under-prospectus-regulation $>$.

20 P Hacker and C Thomale, "Crypto-Securities Regulation: ICOs, Token Sales and Cryptocurrencies under EU Financial Law” (2018) 15(4) European Company and Financial Law Review 645.

21 Regulation (EU) No 596/2014 of the European Parliament and of the Council of 16 April 2014 on market abuse (market abuse regulation), available at <eur-lex.europa.eu/legal-content/EN/TXT/?uri=CELEX:32014R0596>.

22 Directive 2014/65/EU of the European Parliament and of the Council of 15 May 2014 on markets in financial instruments, available at <eur-lex.europa.eu/legal-content/EN/ALL/?uri=CELEX\%3A32014L0065>.

23 To understand MiFID II Directive's improvements over MiFID's initial directive, one may consult <www.esma. europa.eu/policy-rules/mifid-ii-and-mifir $>$.

24 Introductory remark (3) of MiFID II Directive, available at <eur-lex.europa.eu/legal-content/EN/ALL/? uri $=$ CELEX\%3A32014L0065 > .

25 Directive 2009/65/EC of the European Parliament and of the Council of 13 July 2009 on the coordination of laws, regulations and administrative provisions relating to undertakings for collective investment in transferable securities (UCITS) (recast) (Text with EEA relevance). See <eur-lex.europa.eu/legal-content/EN/TXT/?uri=celex\% 3A32014L0091>.

26 Directive 2011/61/EU of the European Parliament and of the Council of 8 June 2011 on Alternative Investment Fund Managers and amending Directives 2003/41/EC and 2009/65/EC and Regulations (EC) No 1060/2009 and (EU) No 1095/2010 Text with EEA relevance. See <eur-lex.europa.eu/legal-content/EN/TXT/?uri=CELEX\% 3A32011L0061>.

27 Another key European financial regulation that we have not mentioned is the European market infrastructure regulation (EMIR) which rules over over-the-counter (OTC) derivatives, central counterparties and trade repositories. See Regulation (EU) No 648/2012 of the European Parliament and of the Council of 4 July 2012 on OTC derivatives, central counterparties and trade repositories, available at <eur-lex.europa.eu/legal-content/EN/ TXT/?uri=CELEX:32012R0648>.
} 
described by Hacker and Thomale (2018) as an "attempt to extend regulation in order to catch up with the ever-changing forms of investment and speculation practices [and] control the dangers they engender for the public".

\section{b. US IPO regulatory regime}

In the US, the Securities Act of 1933 (Securities Act) introduces a requirement that all public offerings of securities must be registered with the Securities Exchange Commission (SEC) ${ }^{28}$ unless they fall within one of the specified exemptions. The Securities Exchange Act of 1934 (Exchange Act), essentially concerned with the secondary trading of securities, introduces additional disclosure and reporting requirements to ensure that investors are properly informed of the risks they potentially incur. In order to protect investors, both statutes also impose a series of liability for any misstatement or omission that would result in deceiving or defrauding the investors. ${ }^{29}$

Because these two statutes only apply to the offering of securities, it is important to define the term. A "security" - as defined in the Securities Act (s 2(a)(1)) and the Exchange Act (s 3(a)(10)) - comprises "any note, stock, bond, debenture, evidence of indebtedness, certificate of interest or participation in any profit-sharing agreement, transferable share, investment contract, investment contract, or instrument "commonly known as a security". The scope of this definition is quite broad; in particular, the notion of an "investment contract" is a catch-all term that could be held to comprise a large variety of financial instruments. ${ }^{30}$ Whether something qualifies as an investment contract is to be assessed in light of the landmark Supreme Court case SEC v Howey $(1946)^{31}$ - which gave rise to the Howey test, ${ }^{32}$ used to determine the legal qualification of financial instruments that do not fit into the traditional categories of securities. ${ }^{33}$ The Howey test is based on four core criteria, which must all be met for a contract to qualify as an investment contract, and therefore as a security: (i) it must have been issued as a result of an investment of money, (ii) into a common enterprise, (iii) with an expectation of profits, (iv) that mostly depends on the work of others. The flexibility of this test is such that, despite having been developed back in 1946, it has been used ever since to bring many new (and irregular) instrument vehicles under the scope of securities law.

\footnotetext{
28 See the Securities Act of 1933 , s 5.

29 See 17 CFR $\S 240.10 b-5$. Note that a material fact has been defined to include any fact that would be important to investors when making a decision to buy or sell securities.

30 See J Dax Hansen and CL Reyes, "Legal Aspects of Smart Contract Applications: Digital Asset Sales and Capital Markets, Supply Chain Management, Land Registries, Government Records and Smart Cities, and Self-Sovereign Identity" (May 2017).

31 See SEC v WJ Howey Co, 328 US 293, 298 (1946).

32 The Howey test dates back to a 1946 case (Securities and Exchange Commission v WJ Howey Co, 328 US 293) whereby it had to determine whether a leaseback agreement should legally be considered an "investment contract", one of the types of investments that is listed as a "security" under the Securities Act of 1933 and the Securities Exchange Act of 1934.

33 See Landreth Timber Co v Landreth, 471 US 681, 690 (1985).
} 
Specific exemptions exist, usually targeted at a certain category of issuers or investors. Regulation $\mathrm{A}^{34}$ - later reformed into Reg A+, following the implementation of s 401 of the Jumpstart Our Business Startups (JOBS) Act in $2015^{35}$ - exempts small and mediumsized companies from the onerous requirement to register with the SEC registration, provided that they do not raise more than US \$20 m (Tier 1) or US \$50 m (Tier 2) in a 12-month period. The general public can invest in these securities offerings, although non-accredited investors ${ }^{36}$ are limited in the amount of money they can invest under Tier 2.

Regulation D (Reg D) - as amended after the implementation of the JOBS Act provides an additional set of exemptions from SEC registration for any company willing to raise capital through an unregistered private offering, ie an offering that is not made available to the public at large, but rather is limited to accredited investors. Rule 504 is concerned with offerings up to US \$5 m over a 12-month period. While it precludes registration with the SEC, issuers must nonetheless fulfil the registration requirements imposed by the laws of each and every state in which securities are offered for sale. Rule 506 is more advantageous because it allows securities issuers to raise an unlimited amount of capital and it preempts blue-sky laws, meaning that issuers do not need to comply with state-based registration requirements. The exemption is split into two options, depending on the manner in which the security offering is done. If the issuers do not wish to engage in general solicitation or advertising to market their securities, they are entitled under Rule 506(b) to sell their securities to an unlimited number of accredited investors and up to 35 non-accredited investors who are sufficiently sophisticated to evaluate the merits and risks of the investment. If the issues do engage in general solicitation or advertising, they are entitled under Rule 506(c) to sell their security only to accredited investors, and the burden is on the issuers to determine that each purchaser does indeed qualify as an accredited investor. While securities offerings done under the Reg D exemption do not need to register with the SEC, issuers are nonetheless required to file a Form D, which comprises a limited amount of information about the company and the offering. Moreover, except in limited circumstances, Reg D requires that securities sold under this exemption be "restricted" in that they cannot be sold on the secondary market for a period of at least six months or a year.

Finally, Regulation S (Reg S) provides a safe harbour for any securities offering undertaken outside of the US, whether it is done by an US or a foreign entity. It relates to both securities issuance on the primary market (Rule 903) and resale on the secondary market (Rule 904). It distinguishes securities offerings into three separate categories. Category 1 imposes the fewest restrictions and, in particular, does not

\footnotetext{
34 This regulation is found under Title 17 of the Code of Federal Regulations, part 230, ss 251-263 - 17 CFR $\$ 230.251 \mathrm{ff}$.

35 The Securities and Exchange Commission adopted final rules to implement s 401 of the Jumpstart Our Business Startups Act by expanding Regulation A into two tiers on 25 March 2015. Reg A+ came into force on 19 July 2015.

36 In the US, the term "accredited investors" is used by the SEC (under Regulation D) to refer to investors who are financially sophisticated and able to properly evaluate the risk and rewards provided by more complex securities and investment opportunities, and therefore have a reduced need for the protection provided by regulatory disclosure filings. They include natural high net worth individuals (ie investors who have a net worth over $\$ 1$ million or an annual income over \$200,000), banks, insurance companies, brokers and trusts.
} 
impose any lock-up period for the resale of securities. In order to benefit from this exemption: (a) the issuer must qualify as a "foreign private issuer" (ie a company owned at least $50 \%$ by a non-US person) that (b) reasonably believes there is no "substantial US market interest" in the securities, and (c) the transaction must qualify as an "offshore transaction", meaning that the offer has not been made to any person located in the US, and the buy order originates from a person that is reasonably believed to be located outside of the US, or the transaction is performed via a foreign security exchange that is located outside of the US. Category 2 applies to any company that fails the requirements for Category 1 but nonetheless qualifies for the reporting requirements of the Securities Exchange Act. It imposes a 40-day lockup period on the resale of securities, along with additional restrictions such as the prohibition to sell securities to US persons even if located outside of the US. Companies that fail to qualify for both Category 1 and 2 (eg US issuers or foreign private issuers that do not file periodic reports with the SEC) may fall under Category 3 , which imposes a lockup period of one year before the securities can be sold on the secondary market.

\section{Policy objectives and underlying principles for the regulation of crowdfunding}

Crowdfunding is generally understood as the act of soliciting a large number of small individual investments or contributions from a large number of people, usually via the Internet. The goal is to collect and commit funds to the achievement of a particular project or initiative - eg the production or provision of a particular good or service - that will ultimately benefit the funders, either directly or indirectly. Crowdfunding is particularly useful for small enterprises, startups and early-stage initiatives that cannot rely on institutional funding sources.

It is possible to distinguish the different modalities of crowdfunding into four distinct categories. ${ }^{37}$

(i) Reward-based crowdfunding, whereby funders receive non-financial rewards in return for their contributions (eg merchandising like t-shirts and CDs, specific privileges such as VIP tickets and backstage access to concerts, or actual products in the case of pre-sales). The rewards or "perks" are usually dependent on the amount of contribution provided by each individual funder, where the greater the contribution the better the rewards will be. Reward-based crowdfunding is often geared towards the support of creative endeavours, like film or music production, concerts, books or other artistic projects. The financial contribution provided by funders is motivated by a combination of intrinsic and social motivations, along with a desire for the rewards. Depending on the modalities, the contributions can be regarded either as a plain donation or as

37 P Pazowski and W Czudec, "Economic Prospects and Conditions of Crowdfunding" in Proceedings of Management, Knowledge and Learning International Conference 2014, 25-27 June 2014, Portoroz, Slovenia, pp 1079-1988, available at <www.toknowpress.net/ISBN/978-961-6914-09-3/papers/ML14-685.pdf> (last accessed 4 July 2019). 
an actual pre-purchase. While the process does not necessarily need to be done via online means, it has become highly popularised with the advent of the Internet, which has spurred the emergence of a large number of crowdfunding platforms Kickstarter and IndieGogo are today two of the most popular examples of this type of crowdfunding. ${ }^{38}$

(ii) Equity crowdfunding, whereby funders are rewarded with an equity stake in a private company in return for their contributions. Funders essentially engage in profits/revenues sharing with the particular business or initiative they are investing in, and can also be granted voting rights. Equity crowdfunding is particularly common for early-stage companies and startups which are not sufficiently established to attract venture capital investments. It can also be used as a form of investment fund, aggregating the funds of multiple small investors that collectively purchase shares in a company; or as a typology of collective investment, whereby the contributions of multiple funders are combined into a large and diversified portfolio. The contribution provided by funders is mostly motivated by financial rewards, as funders generally expect the businesses they invest in to be successful and to generate a significant return on investment, through dividends or shares appreciation. In all cases, the financial contributions can be assimilated to an investment, and the equity stakes granted to the investors are essentially securities.

(iii) Lending-based crowdfunding, whereby borrowers can borrow money directly from lenders, without any financial institution. This type of crowdfunding is used in the context of micro-financing, for early-stage businesses and initiatives seeking debt-based capital, and in the context of peer-to-peer lending, whereby individuals use their savings to issue micro-loans to other individuals in need, at a particular interest rate. Lending-based crowdfunding represents a potential alternative to bank credit, especially in the developing world. Risks are lower because of the direct connection between lenders and borrowers and, where a secondary market for micro-loans exists, systemic risk is also reduced because a lender's strategy is only dictated by the solvency of borrowers in the loan portfolio, rather than on the strategy of other lenders. Yet, because of the peer-to-peer nature of these transactions, financial intermediation is usually done by Internet platforms that connect lenders and borrowers directly. To further reduce risks, these platforms often implement a credit-score system, and retain some of the risk they facilitate (eg by coinvesting in the loans or establishing funds to absorb the first losses).

(iv) Donation-based crowdfunding, whereby individuals donate funds to a particular project or initiative, often with a social or philanthropic purpose, without receiving anything in return. Funders' motivations, in this case, are mostly based on social or intrinsic motivations, and the contributions provided are simple donations.

\footnotetext{
38 According to Investopedia, Kickstarter is the most well-known name in crowdfunding and arguably the most active platform, raising over $\$ 2$ billion since its launch in 2009. Indiegogo comes next, as the second major crowdfunding platform, raising over $\$ 1$ billion since its inception in 2007. See <www.investopedia.com/small-business/topcrowdfunding-platforms/>.
} 
Given the particularities of these different modalities, they do not all fall within the same regulatory framework. Equity-based and lending-based crowdfunding are - by virtue of their financial returns and risk elements - likely to fall under the umbrella of securities regulations, whereas donation-based and reward-based crowdfunding are much less likely to be concerned with these types of regulations.

\section{a. European crowdfunding regulatory framework}

In Europe, crowdfunding represents an alternative to bank lending, which is often difficult to secure for small enterprises and startups who do not yet have any credit history or sufficient collateral. Crowdfunding is generally done via online platforms that operate as intermediaries between the projects, or entrepreneurs, requesting financial support through an open call to the public, and those who provide funds to these projects. However, as of today, the market for crowdfunding in Europe is not as developed as in other parts of the world, most notably the US. One of the main hurdles is the lack of a common regulatory framework across the EU, which significantly increases the compliance and operational costs for crowdfunding platforms willing to offer their services in multiple EU countries.

European crowdfunding regulation essentially distinguishes between investmentbased crowdfunding and lending-based crowdfunding.

Investment-based crowdfunding platforms generally have to be authorised under the MiFID II, and therefore benefit from a passport to carry out regulated services and activities throughout the EU. However, according to Article $3^{39}$ of MiFID II, member states have the option to exempt some firms from registering as an "investment firm" under specific conditions (Art 3.1), and provided they comply with analogous requirements to those required by the Directive (Art 3.2). Under this framework, authorised platforms can carry on crowdfunding-related services and activities at the national level, also in relation to MiFID financial instruments. However, these platforms are not allowed to passport their activities across the EU, unless they seek a full MiFID authorisation.

Lending-based crowdfunding usually entails three main activities: credit intermediation, money handling and debt collection. Lending platforms act as intermediaries providing services that allow borrowers to obtain a (mostly unsecured) loan, and lenders to invest in the loan in exchange for a financial return. Unlike the traditional banking model, lenders, rather than platforms, invest in loans to borrowers, unless platforms also choose to invest their own funds. These investments can yield a higher return than saving accounts offered by banks, but will typically be subject to higher risk. No regulatory safeguards (such as bank deposit guarantee schemes or investor protection schemes) protect these investments. Hence, if the borrower defaults or the platform becomes insolvent, lenders risk losing part or all of their investment. Proper credit risk management and money handling are therefore vital for the viability of the platform in the longer run, and for the protection of lenders and borrowers.

39 See <www.esma.europa.eu/databases-library/interactive-single-rulebook/clone-mifid-ii/article-3-0>. 
The regulatory framework for crowdlending activities significantly differs from one member state to another. Rules range from licensing requirements specific to crowdfunding activity under bespoke regimes to general trade licenses needed at national level in order to operate on the market and to provide consumer credit or credit brokerage services. There are also instances when platforms operate under a payment institution licence under the Payment Services Directive.

These diverging national legislations for both investment-based and lending based crowdfunding make it particularly cumbersome for online platforms to operate across borders. Crowdfunding is thus generally done through national platforms operating in their home market, simultaneously reducing the number of projects that investors can fund and the pool of investors that entrepreneurs can raise money from.

In order to address these issues, the European Commission has launched the FinTech Action Plan, ${ }^{40}$ with a view to establishing a more competitive and innovative European financial sector. As part of this plan, the European Commission recently adopted a proposal for a Regulation on European Crowdfunding Services Providers (Crowdfunding Regulation). ${ }^{41}$ The goal is to establish an optional set of unified rules for crowdfunding in the EU single market, which will operate as a supplement to existing national rules. Hence, any crowdfunding service provider operating in Europe will be able to choose whether to comply with a multiplicity of national regimes, or whether to abide by this unified set of rules that will enable it to operate across borders. We delineate below the core aspects of the proposed regulation.

First of all, in order to operate in the EU single market for crowdfunding, an entity will need to register as a "crowdfunding service provider" with the European Securities and Markets Authority (ESMA) and provide ongoing information concerning its operations and procedural standards. While this registration and authorisation process is more cumbersome than that required by many of the national competent authorities (NCA), it bears the advantage that, once approved, these crowdfunding service providers will obtain a passport enabling them to operate EU-wide crowdfunding offers, without the need to comply with local jurisdictions.

However, the benefits of these EU-wide crowdfunding rules are limited to crowdfunding offers that do not surpass the threshold of $€ 1 \mathrm{~m}$ calculated over a period of 12 months (which is substantially lower than the threshold provided for other national jurisdictions ${ }^{42}$ ). Crowdfunding platforms also need to comply with specific transparency and disclosure requirements in order to protect investors against possible frauds and investment risks. In that regard, crowdfunding service providers are required to provide clear and precise information about the financial risks associated with the projects hosted on their platform, including selection criteria and insolvency risks. They should also make sure that the entrepreneurs or projects seeking public funds through their platform provide prospective investors with a

\footnotetext{
40 See <ec.europa.eu/info/sites/info/files/180308-action-plan-fintech_en.pdf > .

41 See <ec.europa.eu/info/publications/180308-proposal-crowdfunding_en>, and see <www.europarl.europa.eu/ doceo/document/A-8-2018-0364_EN.html> for a full text of the proposal.

42 For instance, in Austria, the Alternative Financing Act (AFA) makes it possible to raise up to $€ 2 \mathrm{~m}$ with a simple informational leaflet, without having to undergo any cumbersome registration and authorisation from the national competent authority.
} 
proper information sheet describing the expected benefits and risks of the investment. Finally, in order to avoid conflicts of interests, crowdfunding service providers are under the obligation to disclose to investors any (financial) relationship they bear with the projects hosted on their platform, and are nonetheless limited in the amount of funds they can contribute to these projects.

This proposed Regulation came along with an additional proposal for a new Directive ${ }^{43}$ amending the MiFID II Directive. The aim is to add crowdfunding service providers to the list of exempted entities to which the Directive does not apply, thereby precluding them from the obligation to obtain a licence as an investment firm.

\section{b. US crowdfunding regulatory framework}

Securities regulations are triggered when investors are committing funds to a project or initiative, in exchange for potential profits generated by others. Many traditional investment instruments fall within these regulations - including stocks, bonds, notes and the broader category of investment contracts. As previously described, in the US, the Howey test had been used for determining whether any given investment qualifies as an investment contract, and should therefore be subject to security laws. Although not designed with crowdfunding in mind, this test is sufficiently broad and flexible to catch a large portion of the investment-based and lending-based crowdfunding activities described above. Hence, for a long time in the US, equity crowdfunding and micro-financing could only be done with accredited investors (in accordance with Regulation D of the SEC regulations).

In many jurisdictions, however, crowdfunding has been specifically exempted from the scope of securities regulations, and has thus been granted a more lenient regulatory framework, intended to strike a balance between the need for experimentation and the demand for more lightweight fundraising procedures for small companies on the one hand, and the need to protect investors against frauds and market failures on the other.

Despite its strict securities regulations, the US has eventually also followed that path. On 16 May 2018, Title III of the JOBS Act came into effect, with a new Crowdfunding Regulation from the SEC, allowing for early-stage businesses and startups to offer and sell securities to the public at large (not only accredited investors) without having to register with the SEC, according to specific conditions.

First, in order to benefit from the exemption, equity crowdfunding must be done via an SEC-registered intermediary - eg broker-dealers or funding portals regulated under the Financial Industry Regulatory Authority (FINRA). Amongst other things, these intermediaries are required to provide educational material to help investors understand their risks, and provide sufficient communication channels to facilitate discussion about their different offerings.

Other limitations apply concerning the amount of funds that can be raised and/or invested. On the one hand, the maximum amount of money that can be raised from crowdfunding over a period of 12 months is limited to $\$ 1,070,000$. On the other

43 See <ec.europa.eu/info/law/better-regulation/initiative/1617/publication/181362/attachment/090166e5b9 153a6a_en $>$. 
hand, investors are limited in the amount of money they can invest over the course of one year. If their annual income or net worth is less than $\$ 107,000$, they cannot invest more than $\$ 2,000$ or $5 \%$ of their annual income or net worth (whichever is higher); otherwise, they can invest $10 \%$ of their annual income or net worth, up to a maximum of $\$ 107,000$.

Moreover, it has to be noted that, if the investment relates to securities, investors are generally prevented from trading these securities for one year, unless they are sold back to the issuer, to an accredited investor, or to a member of the family of the purchaser.

Finally, even if under the Crowdfunding Regulation security issuers do not need to comply with the whole set of SEC regulations, if they raise more than $\$ 100,000$ in funds, they nonetheless need to communicate a prospectus to the SEC, to the intermediary on which the securities are offered, and to the investors. Additional audits must be communicated if the fundraising goes over $\$ 500,000$. The prospectus is much more lightweight than that required under standard SEC regulations. It must include, inter alia, the name of the company's directors, officers, and significant shareholders, along with their business experience; a description of the company's business and business plan; an analysis of the investment's risk; an overview of the company's current financial conditions; as well as the exact price of securities or the method used for determining their price.

\section{The AdVEnt of BLOCKChain teChNOLOGy AND ICOs}

This section will look at how the practices of raising public funds and resources have evolved over the last few years, focusing in particular on the phenomenon of ICOs that emerged with the advent of blockchain technology. To help the reader understand the similarities and distinctive features of an ICO, when compared to other fundraising mechanisms, such as IPOs or equity crowdfunding, we provide here an overview of the general timeline and main steps necessary for undertaking an ICO.

\section{The ICO process}

An ICO consists in issuing a set of "tokens" on top of a blockchain infrastructure, and offering them to the public in exchange for a financial contribution, as a means to raise funds for the development of a particular blockchain-based project or initiative, to which these tokens are inherently linked (see below for an overview of how these tokens might related to the project at hand). So far, a large majority of ICOs have been performed on top of the Ethereum ${ }^{44}$ blockchain (typically using the ERC20 token standard ${ }^{45}$ ). Yet, other blockchain solutions exist (such as Stellar, Neo, ${ }^{46}$ or Waves ${ }^{47}$ to name a few) proposing similar opportunities to token issuers. Though it is not the focus of this paper, compatibility with existing crypto-wallets and the ability to list ICO tokens on crypto-

\footnotetext{
44 See $<$ techcrunch.com/2017/06/08/how-ethereum-became-the-platform-of-choice-for-icod-digital-assets/>.

45 See $<$ theethereum.wiki/w/index.php/ERC20_Token_Standard $>$.

46 See $<$ themerkle.com/can-neo-become-chinas-go-to-platform-for-icos/>.

47 See $<$ wavesplatform.com/ $>$.
} 
exchanges for secondary trading are key elements for token issuers in choosing a particular blockchain solution.

Regardless of the blockchain being used, we can break down a standard ICO timeline into three different phases: (i) prior to, (ii) during, and (iii) after the contribution period, but before the launch of the project. We briefly describe below the main objectives and considerations of each phase.

(i) Prior to the contribution period, a potential token buyer must exercise due diligence in assessing the characteristics of the ICO project, the specificities of the token sale, as well as the success or risk factors attached to it. Additional steps might need to be performed by token issuers for all these token sales which are restricted to accredited investors meeting minimum income or net worth requirements (eg Filecoin ${ }^{48}$ ), or those requiring the identification of all buyers in order to comply with Know Your Customers (KYC) and AntiMoney Laundering (AML) regulations. Because of regulatory pressures in many jurisdictions, these practices of "whitelisting" have been used in a variety of ICOs, such as Aventus, Airswap or Polkadot, etc. ${ }^{49}$

(ii) The contribution period might range from a few seconds (eg Brave's ICO) to a couple of weeks (eg TheDAO), or even a year (as in the case of EOS token sale). The period can be fixed in time, or capped by a particular threshold. Contributions are usually made through dedicated websites owned and managed by the respective project teams. The modalities and amounts of contributions are determined according to different schemes, whose rules are announced to the public prior to the ICO launch. For instance, some ICOs may rely on specific auction mechanisms determining the closure of the contribution period once a specific cap (ie a preset maximum amount) has been reached (eg Gnosis ${ }^{50}$ ); others may be cancelled if a floor (ie a preset minimal amount) has not been attained over the contribution period (eg Snips ${ }^{51}$ ). Moreover, these schemes might include a variety of incentive mechanisms in order to lure people into purchasing more tokens, at an earlier stage. As we have learned from the economics of competitive bidding, ${ }^{52}$ different auction structures might lead to different types of results. It is thus important for token buyers to study and understand the contribution schemes prior to participating in an ICO. Sometimes, however, the auction mechanisms are too complex to be precisely understood by all potential token buyers. ${ }^{53}$ In light of this, specialised ICO firms are emerging with new intermediaries providing technical assistance, advisory and rating services. ${ }^{54}$ Contributors who are unfamiliar with

\footnotetext{
48 FileCoin (August 2017) was the first ICO exclusively restricted to accredited investors.

49 For a list of ICO who have been using an investor's white list as part of their KYC procedure, see < www.reddit. com/r/icocrypto/comments/76elzb/current_list_of_icos_where_whitelist_is_active/ > .

50 See $<$ gnosis.pm $>$.

51 See $<$ snips.ai $>$.

52 PR Milgrom, Economics of Competitive Bidding (Cambridge University Press 1985) p 261.

53 For instance, Polkadot used a Spend-All Second-Price Dutch Auction for their recent ICO (October 2017).

54 The reader may for instance consult $<$ icorating.com $>$ or $<$ icobench.com $>$.
} 
cryptocurrency transactions might get assistance through dedicated online forums and chat channels - such as Reddit or Slack - that fundraisers usually open for this specific occasion. Finally, while contributions have mostly been made with bitcoins or ethers so far, a few ICOs also make it possible to contribute in fiat currency (eg through SEPA wires in Europe). ${ }^{55}$

(iii) Once the contribution period is over, funds (which are typically escrowed by the blockchain-based system that underpins the ICO) are released to those in charge of pursuing the development of the funded project. In many cases, the fundraising teams will try to get the token "listed" on crypto-exchanges to establish a liquid secondary market, allowing token holders to exchange their newly acquired tokens against other crypto-assets ${ }^{56}$ or other listed tokens. Exchanges may also decide to create futures or other types of derivative contracts on the underlying tokens. ${ }^{57}$ As a result, it is not uncommon for investors eager to maximise their short-term financial gains to engage in "hitand-run" (aka "flipping coins") practices, whereby recently acquired tokens are dumped during the first day/minutes/seconds of their listing, thereby significantly decreasing the market value of these tokens. Such risks should be taken into account when considering whether to participate in an ICO, as the high volatility of the token value might significantly increase the financial risk profile of the token sale. In order to prevent these practices, some ICOs introduced a lock-in period, during which investors are unable to transfer their tokens for a particular amount of time after the end of the contribution period. At the same time, lockups on the side of token issuers may also be required to protect token holders. As in the case of IPOs, a lockup over token issuers essentially acts as a "commitment device to alleviate moral hazard problems" $" 58$ derived from the uncertainty surrounding the actions of the managers (aka token issuers) in the aftermath of the offering - as they may not always be motivated to act in the best interests of shareholders (aka token holders in the case of an ICO). In the context of an IPO, a lockup is intended to reduce the ability of insiders to take advantage of investors, by preventing them from executing an early sale of their stock that would reduce their commitment to the company and ultimately disincentivise them to focus on future share price performance. Similarly, ICO lockups are intended to encourage token issuers to focus on the medium-term success of the project, and to reduce their incentives to engage in short-term "sell and resign" strategies. It is interesting to notice that, while ICOs may use two different forms of lockups (one applied to token issuers to protect investors, and the

\footnotetext{
55 DomRaider, for instance, offered their token buyers the possibility to use SEPA wires during their ICO (September 2017).

56 Since the term cryptocurrency has been criticised by various economists, because so-called cryptocurrencies do not meet traditional currency standards, we will use the term crypto-asset which is far less controversial.

57 For instance, HitBTC (<hitbtc.com/>) has a specific ICO trading section while BitMex (<www.bitmex.com/>) offers crypto-asset futures trading.

58 A Brav and PA Gompers, "The Role of Lockups in Initial Public Offerings" (2003) 16(1) Review of Financial Studies 1.
} 
other applied to investors to protect token issuers against "pumps and dumps" schemes), IPOs generally only rely on the former, and do not prohibit investors from selling their newly purchased securities shortly afterwards. Such a restriction would, in fact, be administratively impossible to enforce in the securities post-trade infrastructure, whereas it is relatively easy to achieve on a blockchain-based platform.

\section{Different token types}

While each ICO is unique and idiosyncratic in the way the token sale is designed, the proposed project is framed, and potential investors are reached out to, it is nonetheless possible to categorise the tokens issued by these ICOs into a few broad categories. Indeed, any blockchain-based token is designed to give its holder the option to exercise specific digital rights. The nature of these rights ultimately depends on the infrastructural design of the blockchain-based system on which these tokens have been issued, as well as on the function assigned to (or assumed by) these tokens, ie the various products or services that they provide access to. In addition, insofar as they have been listed on cryptocurrency exchanges, ${ }^{59}$ ICO tokens can be exchanged against fiat currency or other cryptocurrencies.

Depending on the underlying scheme and protocol design, the rights granted to token holders can be exercised in a variety of ways. Some blockchain-based systems might require tokens to be (i) held (ie kept in the holder's account for a particular amount of time); (ii) "staked" (ie locked into the token holder's or a third-party's account); (iii) "spent" (ie transferred to a third-party account); or (iv) "burnt" (ie destroyed after use). Different rights can be obtained or exercised as a result of these functions. For instance, holding a token representing an asset at a certain date can give rights to future dividends; staking a token into a particular account can grant token holders decision-making power proportional to their token stake; whereas purchasing a product or accessing a service might require the token holders to either transfer or burn a specific amount of tokens.

As a general rule, it is possible to categorise the rights associated to an ICO token into four broad categories: (i) rights of usage; (ii) rights of participation; (iii) rights to profits; and (iv) rights of ownership. These rights are not exclusive to one another, in that the same token could simultaneously grant the holder with the right to use a particular blockchain infrastructure, participate in its governance, and/or receive a share of future dividends.

We provide below an example for each of these four categories:

\footnotetext{
59 It would be appropriate to use the term foreign exchange (FX) rate if it was established that crypto-currencies can be indeed considered currencies. This is not the case across all jurisdictions, though in the EU, a landmark judgment was delivered in October 2015 by the Court of Justice of the European Union holding that "transactions to exchange traditional currencies for units of the 'bitcoin' virtual currency (and vice versa) [should be] exempt from VAT under the provision concerning transactions relating to "currency, bank notes and coins used as legal tender", effectively giving Bitcoin a currency status. Source: <curia.europa.eu/jcms/upload/docs/application/pdf/2015-10/cp150128en. pdf $>$.
} 
(i) Right of usage: eg Filecoin is a utility token that enables token holders to use a decentralised cloud storage network; the Golem Network enable tokens holders to access and use a decentralised supercomputer aggregating the processing power of many network nodes; Ether enables token holders to deploy computer code on the Ethereum blockchain and/or transact with it; bitcoins - in addition to being used as a means of payment - also entitle the cryptocurrency holders to using the Bitcoin network as a decentralised payment system. ${ }^{60}$

(ii) Right of participation: eg DAOstack's reputation tokens enable token holders to vote on specific content or governance proposals, where the influence depends on the number of tokens they hold; whereas holders of the MakerDAO's governance tokens (MKR) are entitled to vote for the risk management and business logic of the MakerDAO system.

(iii) Right to profits: eg Polybius digital bank created the Polybius Dividend Tokens (PLBT) in order to reward its investors. At the end of each financial year, $20 \%$ of Polybius' distributable profit is redistributed to the PLBT holders, according to specific conditions; TheDAO ${ }^{61}$ tokens gave holders the right to collect shares of profits generated by the decentralised investment fund. It should be noted that TheDAO tokens were also associated with other rights, such as participation and usage rights.

(iv) Right of ownership: eg the DGX tokens, issued by Digix, act as a certificate of ownership, which can be redeemed for one gram of gold; Tether (USDT), USD Coin (USDC), and Paxos (PAX) are stable tokens ${ }^{62}$ which are - allegedly backed by an equivalent amount of dollars; the Cryptokitties ${ }^{63}$ are nonfungible tokens on the Ethereum blockchain associated with a digital kitty, owned by whoever holds the corresponding token.

Building upon this typology, it is possible to categorise ICO tokens into the following four main functional categories - taking into account that many tokens are likely to fall within one or more of these categories: (i) utility tokens, giving rights of access to a particular product or service; (ii) participation tokens, giving rights to participate in the governance of a specific project; ${ }^{64}$ (iii) investment tokens, giving rights to dividends or other financial returns, based on the profits generated by a particular project; and (iv) asset-backed tokens giving rights of ownership over an underlying asset, be it either a commodity or a specific piece or property. We summarise this typology in Table 1.

It has to be noted, however, that some ICO tokens might have a plurality of functions. For instance, TheDAO token constitutes a governance token (because it provides voting

\footnotetext{
60 It may seem slightly counterintuitive to use BTC as an example of a token giving a right of usage as bitcoins have been identified as a means of payment; however, strictly speaking, spending bitcoins is necessary to use the Bitcoin network. Indeed, even if it is an open and permissionless infrastructure, using the Bitcoin network is not free: today, in order to send bitcoins through the Bitcoin network, one will have to spend a specific amount of bitcoins, as a transaction fee.

61 See $<$ github.com/TheDAO $>$.

62 A stable token is designed to have a constant value in a given reference currency - eg a token always worth $\$ 1$ is a $\$$ stable token.

63 See <www.cryptokitties.co/>.

64 These can also be qualified as "voting tokens".
} 
Table 1. A functional token typology

\begin{tabular}{|c|c|c|}
\hline Token types & Function & Examples \\
\hline Utility token & $\begin{array}{l}\text { Right to access a specific } \\
\text { service provided by a blockchain } \\
\text { system }\end{array}$ & 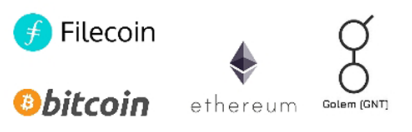 \\
\hline Participation token & $\begin{array}{l}\text { Right to vote or participate in } \\
\text { the governance of blockchain } \\
\text { systems }\end{array}$ & DAOstack \\
\hline Investment token & $\begin{array}{l}\text { Right to receive profits } \\
\text { generated by a particular } \\
\text { blockchain project }\end{array}$ & The DAO \\
\hline Asset-backed token & $\begin{array}{l}\text { Ownership right to a physical, } \\
\text { digital, or intellectual resource }\end{array}$ & $\begin{array}{ll}\text { sigix } & \text { (5) tether } \\
\Leftrightarrow \text { CryptoKitties } & \text { O PAXXos }\end{array}$ \\
\hline
\end{tabular}

rights to the token holders), a utility token (because it enables token holder to submit proposals to the decentralised investment fund), and an investment token (in that it provides some dividends to token holders, based on the profits generated by the projects that the fund has invested in). At the same time, tokens which have been designed with a particular function in mind (eg Bitcoin, Polybius or Digix) might end up assuming a different role in the mind of investors, who might be tempted to purchase a token not because of its intrinsic value (ie the product or service it provides access to) but rather because of an expectation of profits resulting from the speculative dynamics found in the secondary market for that token.

With this in mind, it should be clear that it is not possible to reduce any ICO token to a particular legal category by looking only at the technical implementation of the ICO. One should also consider the function assigned to these tokens, the actual use that is made of that token, and the underlying intentions of the investors at the time of purchase. The regulation of ICOs, and the legal qualification of ICOs tokens, may therefore require a much more in-depth analysis of the contingencies at play within these systems. In the following section, we provide an analysis based on the notion of functional equivalence, in order to determine the extent to which any given ICO may fall within the scope of existing financial regulations.

\section{Functional equivalence for the Regulation of ICOs}

Blockchain technologies provide new opportunities for experimenting with new ways of raising money. Yet, given the specificities of blockchain technologies, it is difficult to establish in which of the existing regulatory frameworks (if any) they should fall into. 
Indeed, while these new fundraising mechanisms present significant similarities with existing fundraising processes, they nonetheless distinguish themselves on a variety of aspects, making it difficult to understand precisely how these new practices should be regulated. Is the issuance of blockchain-based tokens to be considered the same as the issuance of securities? Does a token sale qualifiy as the execution of an investment contract? Can it benefit from the crowdfunding exemption provided by many jurisdictions around the world? This section relies on the doctrine of functional equivalence to analyse whether token sales and ICOs shall be assimilated to existing fundraising practices - and therefore subject to a similar regulatory framework - or whether they are sufficiently different to justify a separate set of rules and regulations.

\section{The concept of "functional equivalence"}

In the late $1990 \mathrm{~s}$, the advent of e-commerce posed several challenges to the existing regulatory framework. The digital environment brought many new opportunities for electronic commerce, enabling users to transfer digital content or other virtual goods through the Internet, and pay for these goods via electronic means. But these new opportunities also came along with many uncertainties as to the way in which existing rules and regulations would apply to these electronic transactions. ${ }^{65}$ First and foremost is the question of the legal classification of these digital goods: Is the sale of a digital music file the same as the sale of a physical disk? Is it possible to rent a digital movie file in the same way as one can rent a VHS in a store? What does it mean to "own" a digital good? etc. Secondly, e-commerce transactions have given rise to many new contract types, such as the Terms of Uses, the so-called "clickwrap" licences, and other flavours of contracts of adhesions. These contractual transactions are no longer signed on paper after a one-to-one negotiation between the parties, but rather are being executed through electronic means. Contractual provisions are made available on a one-to-many basis, via open platforms, and provided "as-is" without any possibility for negotiation.

In spite of the tangible differences that subsist between traditional paper transactions and electronic transactions, the essence of what a transaction is has remained the same. Even if the medium through which transactions are being performed has changed, from a physical medium to a digital medium, online contracts are functionally identical to offline contracts, at least in their objectives: both are intended to provide evidence to a common agreement, giving rise to specific rights and obligations, to which both parties have indicated their willingness to be legally bound. It naturally follows that electronic contracts should be subject to the same provisions of traditional contract law, and therefore abide by the same rules in terms of contract formation, performance, and remedies. It does not follow, however, that every electronic contract will always and necessarily qualify as a valid contract. Quite to the contrary, like any other contractual agreement, an electronic contract needs to fulfil certain conditions in order to be considered both valid and enforceable - these include offer and acceptance, consideration, informed consent, writing requirement, etc. Each of these conditions

65 EJ Koops et al, "Should ICT Regulation Be Technology-Neutral?" (2006) 9 IT \& Law. 
needs to be met, regardless of whether parties are contracting in the physical or digital world. Far from having become obsolete, contract law therefore came to be regarded as a crucial body of law capable of accommodating these new contracting practices and regrouping them within the same general category of contracting, in spite of their technical differences.

Yet, given that contract law was elaborated before the advent of Internet and digital technology, many provisions refers to specific legal concepts which are inherently bound to a tangible medium. These include the notions of a "document", an "original", or even a "signature" or the act of "writing" - none of which had been properly defined in the digital realm. Hence, in order to properly encompass electronic transactions and other online practices, some adaptations to the law were nonetheless required. ${ }^{66}$

For the purposes of e-commerce, a preliminary step in that direction was taken through the United Nations Commissions on International Trade Law (UNCITRAL)'s Model Law on Electronic Commerce (MLEC), aiming to establish a series of principles to give electronic transactions the same level of legal recognition as traditional paperbased transactions, without requiring any extensive legal reform. This was done via the introduction of the principle of functional equivalence, as a means of incorporating electronic transactions in the context of traditional contract law. ${ }^{67}$

Of course, the principle of functional equivalence needs to be applied not only at the level of the contract itself, but also at the level of all of its constitutive elements. Indeed, the MLEC stipulates that the "purposes and functions of paper-based requirements may be satisfied with electronic communications, provided certain criteria are met". ${ }^{6}$ Accordingly, to establish functional equivalence, one must identify the appropriate technical features that are necessary to replicate specific paper-based requirements (such as writing, signature, original, etc). For instance, the requirement for a contract to be in "written form" could be satisfied so long as the electronic transactions remained accessible for future reference. Similarly, a digital signature can be regarded as being functionally equivalent to a paper signature to the extent that it can be attributed to a unique person and that it possesses the properties of authenticity, integrity, and nonrepudiation.

Coming back to blockchain technologies, it might be worth investigating whether the same principle of functional equivalence could be applied in the context of ICOs, with a view to identifying, on the one hand, whether some blockchain-based tokens could be regarded as being functionally equivalent to traditional financial instruments, such as stocks or securities, and, on the other hand, whether some tokens might qualify as a new asset-class that should therefore be regulated according to a more sui generis framework.

\footnotetext{
66 C Reed, "Online and offline equivalence: aspiration and achievement" (2010) 18(3) International Journal of Law and Information Technology 248.

67 PP Polanski, “Convention on E-Contracting: The Rise of International Law of Electronic Commerce?" BLED 2006 Proceedings, 20.

68 L Castellani, "The contribution of UNCITRAL texts to paperless trade", United Nations Commissions on International Trade Law.
} 
In a large majority of jurisdictions - with the exception of the US perhaps, whose common law doctrines are sufficiently flexible to cover many of these new fundraising practices ${ }^{69}$ - most of the tokens issued during an ICO do not qualify, strictly speaking, as any existing asset class, and therefore do not fall within the scope of any existing regulatory framework. This is especially true in the case of civil law countries, like France, Germany, or other European countries, which provide a very clear and precise definition of every asset class, along with all of its constitutive elements. $^{70}$

Just like electronic contracts have been deemed to be functionally equivalent to traditional paper-based contracts - not just because they share the same purpose, but because they present elements which are themselves equivalent to the constitutive elements of a contract - it is worth investigating whether we could rely on the same concept of functional equivalence in order to get some of the ICO tokens to qualify for instance as securities, shares, stocks or other financial instruments. When analysing the legal aspects of an ICO, it is therefore useful to identify what are the distinctive features of a token, which - in specific circumstances, depending on the technical design and practical use of that token - might qualify as being functionally equivalent to a particular asset class. ${ }^{71}$

As in the case of e-commerce, where electronic transactions were brought into the realm of traditional contract law without bringing any changes to the law, also in the case of blockchain-based financial instruments, provided that all constitutive elements are met - albeit in a different format than what was originally envisioned under the law - it might be unnecessary to reform existing regulations, or even create new regulations, and rely instead of the principle of functional equivalence in order to ensure that these tokenised assets are brought within the scope of an existing regulatory framework and therefore remain under the purview of the law.

It is, of course, unlikely that all tokens will qualify as an existing asset class, as Sontakke and Ghaisas have pointed out. ${ }^{72}$ Some tokens might ultimately not fit into any existing categories because they are actually different both in their nature and function, or simply because they lack some of the core constitutive elements of that class. Other tokens may be regarded as hybrid entities, with regard to existing categories - just as convertible bonds exhibit both equity-like and fixed income features.

In that regard, drawing from the functional classification of token types presented above, it appears that, while asset-based tokens and participation tokens - in their purest form - do not seem to raise any specific issues with regard to securities laws, the situation is much more blurry when an ICO entails the sale of investment tokens and utility tokens, which could to a large extent fall under the umbrella of IPO or

\footnotetext{
${ }^{69}$ See eg the Howey test, according to which the sale of a large variety of ICO tokens might be held to qualify as an investment contract.

70 For an in-depth overview of the distinction between civil law and common law approaches to securities regulation, see P De Filippi et al, "Regulatory Framework for Token Sales: An Overview of Relevant Laws and Regulations in Different Jurisdictions" (2018) COALA \& Blockchain Research Institute Big Idea Whitepaper.

71 F Wang et al, "Financing Open Blockchain Ecosystems: Towards Compliance and Innovation in Initial Coin Offerings" (2018) COALA \& Blockchain Research Institute Big Idea Whitepaper.

72 KA Sontakke and A Ghaisas, "Cryptocurrencies: A Developing Asset Class" (2017) 10(2) International Journal of Business Insights \& Transformation 10.
} 
crowdfunding regulations. The following analysis will thus focus specifically on the latter two categories of tokens.

\section{Investment tokens}

The objectives of an IPO are relatively simple: the issuing company is looking to raise capital in public markets. The decision to go public is often many-sided, but it usually reflects two core motivations: (i) access to funding, ie the will of management/existing shareholders to tap into a larger pool of investors and raise substantial amounts of capital that would be difficult to find with private placements; and (ii) liquidity, ie the desire to provide existing shareholders (seed investors, business angels, venture capitalists and so forth) with an easy exit for their investment. It would be an oversimplification to state that IPO investors are essentially buying into IPOs because of the pursuit of financial profit. Yet, if we look at the large institutional investors that usually partake in IPOs, it is clear that they are constrained by fiduciary duties, and that their primary objective is to achieve the best possible financial returns for their shareholders.

As the name suggests, an ICO shares many similarities with an IPO. Both are used as a means to raise public funds for the development of a project or initiative through the sale of a particular asset, and both represent an important opportunity for previous shareholders (or token holders in the case of an ICO) to close their position to achieve a return on investment.

Sometimes, the tokens issued through an ICO might actually represent an equity share or a company stock (investment token). For instance, shares of a company can be "tokenised" and stored on a blockchain-based network, in order to facilitate the trading thereof via a secure, authenticated and immutable ledger. These ICOs are sometimes referred to as Securities Token Offering (STOs), because they are essentially focused on the issuance of securities through a blockchain-based infrastructure. This is precisely what the tZERO platform is intended to achieve, providing a platform that integrates blockchain-based technologies with existing market processes "to reduce settlement time and costs, increase transparency, efficiency and auditability" in capital markets. ${ }^{73}$ As opposed to most ICOs thus far, which generally have tried to avoid their tokens being qualified as a security, the tZERO ICO has actually been characterised by its own team as a "security token sale" - thereby explicitly trying to bring the tZERO token into the realm of securities. What's more, the platform provides a generalised way for companies to issue their own stocks on a blockchain in order to create a secure and decentralised marketplace for private equity. Although they rely on an entirely new technology, these tokenised shares are, for every practical purpose, equivalent to traditional shares.

Accordingly, whenever a token constitutes a blockchain-based representation of an equity share or stock, it is possible to rely on the doctrine of functional equivalence to argue that the issuance of these tokens should be regulated in exactly the same way as the issuance of traditional securities. Indeed, whether a stock is represented

73 See $<$ tzero.com $>$. 
via a piece of paper or via a blockchain-based token does not at all modify the function of that asset.

There are both benefits and drawbacks to such an approach. One the one hand, the inclusion of an ICO within the umbrella of securities law means that token issuers will need to comply with a series of obligations and constraints that they would not have to account for otherwise. On the other hand, falling into regulated waters also provides an additional degree of protection, to the extent that token issuers might be exempted from any additional liability risk, provided that they fulfilled the requirements of all relevant laws and regulations.

In many cases, however, these benefits do not outweigh the costs, and token issuers will therefore try to frame their ICO in such a way as to bring it outside of the scope of securities law. In fact, while the objectives and operations of an IPO are clear and established, those of an ICO are generally more varied and difficult to reduce into a single category.

First of all, while both IPOs and ICOs are both intended to acquire resources for the development of a specific project or initiative, as opposed to IPOs (which are generally done after a company has achieved a sufficient level of maturity), ICOs are generally done at a much earlier stage, to facilitate the bootstrapping of a particular project or initiative. As such, an ICO shares several similarities with traditional crowdfunding practices, since, when it comes to fundraising, both contribute to lowering the costs of acquiring external funds. New startups typically struggle to attract externally-sourced working capital early on in their corporate histories - be it venture capital equity or bank loans, as the work of various scholars has shown. ${ }^{74}$ ICOs and other crowdfunding practices enable entrepreneurs and communities to finance new and experimental projects that would otherwise be unable to rely on classical financing channels.

Moreover, in the context of many ICOs, although raising funds is the primary objective, they are often other non-financial considerations that can also be found in crowdfunding. IPOs typically allow corporates that have acquired a certain size and stability of revenues to raise funds from various institutional investors, who will, for the most part, remain passive investors. In contrast, drawing a precise line between investors, consumers or supporters is not always easy - or even feasible - in the context of both ICOs and crowdfunding, where those who provide the funds are also those who want to access the service or use the product they are funding. Although many ICO investors are motivated by the expectations of financial gains and do not bother to engage in the governance of the projects they funded, in many other cases, ICOs participants, just like the many backers of a crowdfunded project, are not just seeking the pursuit of financial profits. They want to have a "say" in the project (not just a "stake") and are thus more likely to actively contribute to the success of the project, all the more if they "enjoy community benefits that increase their utility". 75

\footnotetext{
74 On this topic, see P Belleflamme et al, "Crowdfunding: Tapping the right crowd" (2012) 29(5) SSRN Electronic Journal; A Berger and G Udell, "Relationship lending and lines of credit in small firm finance" (1995) 68(3) Journal of Business 351; G Cassar, "The Financing of business start-ups" (2004) 19(2) Journal of Business Venturing 261; A Cosh et al, "Outside entrepreneurial capital" (2009) 119 Economic Journal 1494.

75 This last point is in fact assumed in Belleflamme et al, supra, note 74 .
} 
As such, network effects also play a more crucial role in the context of ICOs than they do in the context of traditional IPOs. Not only do they allow for a small community to potentially grow larger at a very fast pace, they also bring together a community of testers and early adopters who can help the initial project go "viral". Once the ICO is completed, the token value will grow in line with the size of the community of users. Hence, similarly to crowdfunding, an ICO puts in place a virtuous circle, whereby token holders also become clients or consumers of the products or services they have funded.

Accordingly, although some ICOs can be assimilated to an IPO, the objectives and operation of a majority of them are much closer to that of equity crowdfunding. In line with the doctrine of functional equivalence, it is thus fair to assume that - to the extent that they can comply with the regulatory constraints imposed by crowdfunding regulations - an ICO could benefit from the crowdfunding exemptions that have been introduced both in Europe and in the US, along with many other jurisdictions.

Yet, in order to benefit from these exemptions, token issuers need to comply with the stringent conditions required by crowdfunding regulations, with regard to the limits on the amount of funds that can be raised or invested, on the one hand, and the necessity to operate through a registered intermediary, on the other hand. Indeed, while crowdfunding is usually performed over a centralised digital platform (eg Kickstarter or Indiegogo), in charge of curating, monitoring and, to some extent, managing the projects for which funds are being sought, an ICO is typically done over a decentralised infrastructure enabled by blockchain technology, and does not therefore involve any trusted authority responsible for the curation and supervision of projects.

In light of these constraints, many token issuers have chosen not to confine themselves in the realm of crowdfunding, and have been trying instead to escape from the scope of regulation by highlighting the fact that - despite the functional equivalence between these different fundraising practices (with regard to both IPOs and crowdfunding) - there are also important differences that may place ICOs outside of regulated waters.

Perhaps the most important difference between ICOs and equity crowdfunding or IPOs is that, because a blockchain-based infrastructure makes it possible to raise funds for projects that do not have a corporate structure, ${ }^{76}$ in many cases, the type of assets that are being offered to the public through an ICO are significantly different from those of an IPO. An IPO is concerned with the issuance of a company's stock that will dilute the overall ownership of the company. It typically implies a dilution of shareholding rights (and hence of corporate control) for existing shareholders - unless they are able to acquire newly issued shares in proportion to their existing stakes. Because the bearer of a company's shares usually gets both economic and voting rights, by diluting existing shareholders, an IPO dilutes the existing shareholders' control over the company, as well as their economic rights over the dividends to come.

An ICO, instead, generally refers to the issuance of blockchain-based tokens that do not necessarily have a direct connection with a company - except where the tokens represent actual shares in a company (eg in the case of an STO). As a general rule, while there is often a company involved with the project or initiative that will be

76 In all fairness, this is also true of many crowdfunded projects, although in the context of crowdfunding there is always a centralised platform (eg Kickstarter or Indiegogo) acting as the referent. 
funded through the ICO, the tokens are issued through a foundation that will be in charge of collecting the proceedings. In the most extreme cases, funds are sent directly to a cryptocurrency account controlled by a handful of people, without any legal entity. Hence, regardless of whether or not there is a corporate entity backing the project, token issuance does not actually dilute the ownership of a legal structure. There is generally no dilutive effect in terms both economic and voting rights, because the tokens issued are independent from the actual shares of a company (except in the case of security tokens).

However, although there is no formal or corporate dilution, it should be noted that, in practice, an ICO might also lead to a redistribution of both voting and economic power among investors, to the extent that tokens are used as a proxy to an economic interest and decision-making power. Hence, even though the form changes, the function once again - remains the same.

$\mathrm{TheDAO}^{77}$ represents perhaps the most notorious example of how a blockchain-based initiative without any corporate entity ultimately operates like a traditional corporation. TheDAO was a decentralised organisation acting as an investor-directed venture capital fund, which initiated its token sale in May 2016. Even though it had no legal entity, TheDAO was designed from the start to mimic - and allegedly improve - corporate governance. Participants who acquired TheDAO's tokens automatically acquired the ability to vote on the projects that TheDAO would fund (proportional to each participant's stake), and the right to collect a portion of the profits generated by previously funded projects. ${ }^{78}$ Thus, despite TheDAO not being directly backed by any corporate structure, participants in TheDAO's ICO had similar expectations to standard IPO investors: acquiring some degree of control over the direction of the project and TheDAO's investment decisions (decision-making power) and obtaining a share of its future profits (economic interest).

The similarity of TheDAO tokens with traditional securities did not pass unobserved. On 25 July 2017, the US SEC issued an investigative report stipulating that digital assets offered and sold by "virtual organisations" are subject to the requirements of the federal securities laws to the extent that they de facto operate as securities. ${ }^{79}$ While, in the end, the agency decided not to bring retroactive charges in this instance (because TheDAO had already came to an end due to a technical glitch), the report sent a clear warning to current and future tokens issuers that their activities might fall within the scope of SEC regulations.

\section{Utility tokens}

While many ICOs have been framed or perceived as a form of investment by both token issuers and token holders, and are therefore likely to qualify as securities issuances, many

\footnotetext{
77 For further details, we recommend reading the introductory section of TheDAO's white paper available at $<$ download.slock.it/public/DAO/WhitePaper.pdf $>$.

78 The DAO had an objective to provide a new decentralised business model for organising both commercial and nonprofit endeavours.

79 The press release can be found at <www.sec.gov/news/press-release/2017-131>, while the report itself, dubbed the "21(a) Report" by Chairman Clayton, as it refers to s 21(a) of the 1934 Securities Exchange Act, is available at $<$ www.sec.gov/litigation/investreport/34-81207.pdf $>$.
} 
people (especially token issuers) believe that, regardless of the amount of funds to be raised, ICOs should remain outside the regulatory framework of IPOs - whose expensive formalities and draconian regulations might stifle innovation in the blockchain space.

Hence, in order to escape from the doctrine of functional equivalence, token issuers have been experimenting with alternative ways of framing their tokens as something that is functionally not equivalent to a security. This is what motivated the narrative towards the issuance of "utility tokens" - ie tokens that represent mere access to a particular product or service, rather than a speculative investment. Inspired by the different types of crowdfunding, token issuers argue that because of the intrinsic functionality of these tokens, the issuance of utility tokens to the public at large should merely be regarded as a standard "pre-sale" contract (as opposed to an investment contract), which should therefore not fall under the umbrella of securities regulations.

As described in the previous section, traditional crowdfunding typically takes the form of an equity stake, a loan, a donation, or a reward-based pre-order ${ }^{80}$ but only the former two are regarded as regulated activities under financial regulations.

Blockchain-based tokens might acquire a different legal status depending on the token design and the intended or perceived function of these tokens. At its core, any ICO that does not entail the sale of an equity share or a company stock (as in the case of STOs) leverages the opportunities of blockchain technology to collect public funds for the development of a particular project or initiative, and could therefore be regarded as a new form of reward-based crowdfunding. Indeed, although not formally presented as such, the tokens issued through an ICO generally represent a variety of rights (present or future) that can be assimilated to those traditionally granted via reward-based crowdfunding.

Yet, regardless of the narrative used by token issuers, it is important to assess whether utility tokens - in spite of their distinct functionality - could nonetheless qualify as a security, to the extent that they fall within the broader category of an investment contract. Token issuers might well try to design their ICO in such a way that their token falls outside of any existing regulated category, but they cannot run afoul of security regulations so easily.

For instance, in the US jurisdiction, many token issuers have intentionally sought to fail the Howey test, by making sure that at least one of the four conditions is not met. ${ }^{81}$ However, since the US SEC has endorsed the principle of "substance over form", 82 it has become clear that one cannot run afoul of SEC regulations by simply stepping aside from

\footnotetext{
80 Pazowski and Czudec, supra, note 37.

81 In the Howey test, the US Supreme Court defined an "investment contract" as any "contract, transaction or scheme whereby (1) a person invests his money (2) in a common enterprise and is (3) led to expect profits (4) solely from the efforts of the promoter or a third party".

82 On 11 December 2017, SEC Chairman Clayton made a statement on cryptocurrencies and ICOs, warning token issuers not to "highlight utility characteristics of their proposed initial coin offerings in an effort to claim that their proposed tokens or coins are not securities". He further reminded that "many of these assertions appear to elevate form over substance" in an effort to dodge existing securities regulation. See <www.sec.gov/news/public-statement/ statement-clayton-2017-12-11>.
} 
a formal requirement: a token will be regarded as a regulated security if the substantive function of that token remains that of an investment contract.

The only way to assess the substantive function of a token is to investigate the intentions of the people purchasing these tokens. While the backers of a reward-based crowdfunding project are mostly interested in the practical implementation of the projects they are funding - in order to directly benefit from them, as opposed to make money out of it - investors in an ICO have more ambivalent motivations: in addition to their interests in seeing the project come to life, they are also (or mostly) interested in acquiring a particular set of tokens, whose value might fluctuate over time - with a view to generate financial gains by trading these tokens on a secondary market.

This issue was clearly illustrated by the Munchee case, which represents an important precedent for all token issuers claiming that their tokens are primarily designed as a utility token when, in fact, investors had "reasonable belief that their investment in tokens could generate a return on their investment". ${ }^{83}$ Munchee Inc was a California-based company that intended to launch an ICO to fund its blockchain-based food review service. However the SEC found that - despite the utility ascribed to its tokens - public issuance of these tokens would constitute "unregistered securities offers and sales"; 84 the company had to terminate the ICO and refund investors before any tokens were issued.

Moreover, it has been shown that, even if blockchain-based tokens do not qualify as a security at the time of issuance, their qualification can always be re-evaluated ex post by the SEC, who might declare that these tokens have eventually become a security. ${ }^{85}$ As a result, many token issuers - by fear of falling within the scope of the Howey test - have excluded US operations and US persons as potential participants to their ICOs.

With this in mind, it becomes clear that any attempt by token holders to escape from a particular regulatory framework (and securities laws in particular) by simply describing the token as a "utility token" and assigning a specific utility value to it (eg a right of usage or a right of participation) will not be sufficient to justify a regulatory exemption. Indeed, the doctrine of functional equivalence - which requires looking at the policy objectives that motivated the creations of specific rules and regulations, to understand whether these rules have reason to apply into this new context - is sufficiently broad to catch not only investment tokens, but also utility tokens that ultimately assume the same function as a security.

\footnotetext{
83 ibid.

84 See <www.sec.gov/news/press-release/2017-227>.
}

85 This ability that regulators have to act retrospectively was exercised by the SEC in the case of TheDAO as it published on 25 July 2017 (slightly over a year after TheDAO ICO took place) a Report of Investigation Pursuant to Section 21(a) of the Securities Exchange Act of 1934. This investigation reiterated the "fundamental principles of the US federal securities laws and [described] their applicability to a new paradigm - virtual organisations or capital raising entities that use distributed ledger or blockchain technology to facilitate capital raising and/or investment and the related offer and sale of securities". The SEC also made it clear that "the automation of certain functions through this technology [ . . ] does not remove conduct from the purview of the US federal securities laws" (source: $<$ www.sec.gov/litigation/investreport/34-81207.pdf $>$ ) The agency decided not to bring "charges in this instance, or make findings of violations in the Report, but rather to caution the industry and market participants" (source: $<$ www.sec.gov/news/press-release/2017-131>). 
V. A PRINCIPLE-BASED APPROACH TO REGULATION: FROM "FUNCTIONAL EQUIVALENCE" TO "RISK EQUIVALENCE"

Traditionally, the doctrine of functional equivalence is regarded as a means to bring new technological developments under an existing regulatory framework, to the extent that the activities facilitated by a new technology fulfil the very same functions as the preexisting activities relying on previous technologies (eg paper-based contracts and electronic contracts).

However, regulation is not solely determined by the qualities or functions of a particular asset class, or by the objectives or purposes of a particular activity, but also by the risks that such asset or activity entail. In the realm of finance, in particular, many rules and regulations are motivated, to a large extent, by the need to reduce risks for investors. Hence, a proper application of the doctrine of functional equivalence in this field should not be limited to a mere analogy with the functionalities of different fundraising practices, but should also focus on the similarities between the risks associated with different types of token sales.

On the one hand, depending on the contextual framework, two identical activities could be regulated differently, to the extent that they are characterised by different degrees of risk. For instance, in the case of equity crowdfunding, even though it fulfils the exact same function as an IPO (ie publicly raising funds for a private company going public, in exchange for a promise of returns on investment), it is not regulated in the same manner, because the risks associated with equity crowdfunding are - by virtue of the smaller amount of funds that can be invested into this type of endeavour - much lower than the risks associated with an IPO.

On the other hand, two activities that substantially differ from one another (eg the issuance of a company stock versus the issuance of a token that is not associated with any company) could be regulated in the exact same manner to the extent that they give rise to a very similar set of risks. Thus, even if there is no strict functional equivalence between a security token and a utility token, both could be regulated in a similar manner insofar as the risks they entail are the same.

The blockchain ecosystem, and in particular the ICO space, is characterised by a wide range of new business practices that do not have a precise equivalent in the offchain world. As a result, it can be somewhat difficult to rely on a strict interpretation of the doctrine of "functional equivalence" in order to establish the extent to which a particular token sale should be regarded as being functionally equivalent to a more traditional IPO. Indeed, given the ability for token issuers to innovate with these new technological artefacts and to set up their token sales in ways that will formally distinguish them from a traditional IPO, such a strict interpretation of functional equivalence would enable some ICOs to escape from the realm of security regulations, even if they carry the same functions and risks.

The variety of token classifications that are being put forward (eg utility tokens, participation tokens, investment tokens, asset-backed tokens) are of limited utility from a regulatory perspective to the extent that the same token can - regardless of its intended function - be used in many unintended manners, and therefore de facto qualify both as a payment token and as a security token. This creates specific 
challenges for regulators because, when trying to determine the proper level of regulatory constraints that an ICO should be subject to, not only do they need to assess the original nature or function of the tokens being issued (whether they are of the utility, payment, investment or asset-backed type), but also look into the underlying motivations of both token issuers and investors (why are they issuing the tokens; why and by whom are the tokens being purchased?), as well as the risks that investors may incur in purchasing these tokens - which might extend beyond the control (and intentions) of the original token issuers.

We propose here an alternative approach to functional equivalence, focusing not only on the underlying functions assumed by these token sales, but also - and most importantly - on the underlying principles that motivate the regulation of these new fundraising practices, with regard to both the risks and benefits they might bring to investors. It is our belief that such a principle-based approach to the regulation of ICOs will lead to a more legitimate and efficient type of regulation by moving from "functional equivalence" to "risk equivalence". Indeed, if the regulation of IPOs is intended to protect investors from tangible risks, then analysing the risks created by ICOs is perhaps the most efficient way to determine the extent to which these new business practices should qualify as regulated activities, and whether they should be subject to the regulatory constraints as traditional IPOs.

\section{Principle-based regulation}

When contemplating if and how to regulate ICOs, it is interesting to look back at the lessons from the last financial crisis. It seems quite clear, in retrospect, that an important factor leading to the crisis was an unprecedented degree of complexity in some financial products that made it difficult for some market participants to clearly understand the overall degree of systemic risk at the macroeconomic level on the one hand, and the particular features of the products they were buying into, at the microeconomic level, on the other hand.

This degree of complexity was essentially achieved by a string of financial innovations. As Awrey puts it,

"complexity and innovation [...] have combined to generate significant asymmetries of information and expertise between public regulators and private (regulated) actors and exacerbated the agency problems that pervade global financial problems [...] Identifying the optimal policy response to the complexity and nature and pace of innovation within financial markets is, accordingly, vitally important in terms of the delivery of effective financial regulation". ${ }^{86}$

Of course, regulating a complex and rapidly changing technology is not easy; regulations have to constantly adapt and adjust their rules to the new technological landscape. ${ }^{87}$ Rules

\footnotetext{
86 D Awrey, “Regulating Financial Innovation: A More Principles-Based Proposal?” (2011) 5(2) Brooklyn Journal of Corporate, Financial \& Commercial Law 273.

87 P De Filippi, "Bitcoin: a regulatory nightmare to a libertarian dream" (2014) 3(2) Internet Policy Review.
} 
1090

1091

1092

1093

1094

1095

1096

1097

1098

1099

1100

1101

1102

1103

1104

1105

1106

1107

1108

1109

1110

1111

1112

1113

1114

1115

1116

1117

1118

that try to be overly specific for the sake of clarity and compliance, will soon have to change because of technological advances.

This is where principles-based regulatory frameworks come in handy. In a nutshell, a principles-based regulation (as opposed to a rules-based one) mainly focuses on the principles that should be followed in any relevant situation, instead of trying to establish a set of rules that should address all possible scenarios. This approach to regulation has the advantage of flexibility, while the drawback is that honest or illintentioned individuals may invoke different interpretations of the principles at work to justify their own courses of action.

Without revisiting the history of the "rules vs principles" dialectic, ${ }^{88}$ it seems fair to say that, while principles-based regimes were pursued by the UK Financial Services Authority (FSA), the Australian Securities and Investment Commission (ASIC) and other jurisdictions (most notably Canada before the 2008 crisis), this approach was thereafter criticised as having opened the door for various abuses due to its perceived lack of precision. Awrey (2011) fought back these criticisms, by showing that a principles-based regulation could be particularly suitable to deal with over-the-counter (OTC) derivatives markets, where asymmetries of information and agency problems are pervasive. In Awrey's words, if “modern financial markets are characterized by complexity, seemingly perpetual innovation, chronic asymmetries of information and expertise, and pervasive agency costs", prescriptive, rules-based approaches toward financial regulation have thus far "proven inadequate to [the] task" and principlebased regulation has the potential to "overcome these challenges and, in the process, generate more nuanced, responsive, durable, and effective regulation".

Accordingly, despite the acceptable criticism of the leeway that a principles-based regulatory approach may give to fraudsters, we think it is worth considering this general paradigm for dealing with ICOs - especially when it comes to risks. ${ }^{89}$ With this in mind, we now turn to a comparison of the risks raised by both IPOs and ICOs, as we believe it is particularly relevant to the debate of how to best regulate these emerging fundraising practices.

\section{Comparing risks between IPOs and ICOs}

Academic literature has already analysed the various risk factors of IPOs and their link to financial returns and long-term performance. For instance, Abdou and Dicle have found that "venture capitalists and investment bankers have a significant and economic effect on the number of risk factors reported in the prospectus", ${ }^{90}$ while Bhabra and Pettway have shown that prospectus information is "more useful to predict survival/failure compared to

\footnotetext{
88 See eg J Black et al, "Making a success of principles-based regulation" (2007) 1(3) Law and Financial Markets Review 191; J Black, "Forms and paradoxes of principles-based regulation" (2008) 3(4) Capital Markets Law Journal 425; C Ford, "Principles-based securities regulation in the wake of the global financial crisis" (2010) 55(2) McGill Law Journal 257; JJ Park, "Rules, principles, and the competition to enforce the securities law" (2012) Cal L Rev 100 at 115.

89 S Arjoon, "Striking a balance between rules and principles-based approaches for effective governance: A risksbased approach" (2006) 68(1) Journal of Business Ethics 53.

90 K Abdou and MF Dicle, "Do risk factors matter in IPO valuation?" (2007) 15(1) Journal of Financial Regulation and Compliance 63.
} 
subsequent equity offerings or acquisitions" ${ }^{91}$ As many of the formalities required by securities law are driven by the motivation to properly inform potential investors, the risks entailed by an offering need to be properly accounted for by the quantitative and qualitative information provided in the offering prospectus.

Given the described parallelism between ICOs and IPOs, it is natural to think that they should entail common risk factors. ${ }^{92}$ Whether they come from an IPO or an ICO, similar risks should be treated in a similar manner. Hence, if the risks posed by an ICO are equivalent, in degree and in kind, to those posed by an IPO, there are good reasons to believe that the two fundraising practices - albeit different in their objectives and format - should nonetheless be subject to a similar regulatory framework. Indeed, from a "risk equivalence" perspective, similar risks shall give rise to similar regulatory constraints, regardless of format or the declared function of these token sales.

Yet, there are important differences between an ICO and a more traditional fundraising operation, which might significantly affect the risk-profile of the projects funded via either of these methods. In order to better understand the differences and similarities, this section will provide an overview of the common risk factors between IPOs and ICOs, and then provide a more detailed analysis of the risks that are idiosyncratic to an ICO.

\section{a. Common risk factors between ICOs and IPOs}

As we have seen before, the regulation of IPOs is largely intended to reduce the degree of information asymmetries between securities issuers and investors, in order to ensure a properly functioning market. The regulation of ICOs face a similar challenge: information asymmetries between token issuers and investors represents a major risk for this emerging market. As a result, investor and consumer protection regulations developed for IPOs could also be relevant in the context of ICOs. In particular, because of the immature markets for ICOs and the significant information asymmetries that characterise them, it is especially important to insist on the need for investor and consumer protection. For instance, a study prepared by ICO advisory firm Satis Group revealed that "more than 80 percent of initial coin offerings conducted in 2017 were identified as scams", though they "received very little funding when compared with the industry as a whole". ${ }^{93}$ Indeed, according to the same study, if "total funding of coins and tokens in 2017 amounted to $\$ 11.9$ billion", only " $\$ 1.34$ billion (or 11 percent) of ICO funding went to scams" - with the vast majority of the funds going to three main projects..$^{94}$

\footnotetext{
91 HS Bhabra and RH Pettway, "IPO prospectus information and subsequent performance" (2003) 38 Financial Review 369.

92 MR Meadows, "The Evolution of Crowdfunding: Reconciling Regulation Crowdfunding with Initial Coin Offerings" (2017) 30 Loy Consumer L Rev 272.

93 See <cointelegraph.com/news/new-study-says-80-percent-of-icos-conducted-in-2017-were-scams >.

94 See p 25 of Satis Group Crypto Research report "Cryptoasset Market Coverage Initiation: Network Creation", dated 11 July 2018, available at < research.bloomberg.com/pub/res/d28giW28tf6G7T_Wr77aU0gDgFQ > . Though we have not found precise figures in the case of IPOs, these ICO figures are likely to be much higher than their IPO counterparts - whether referring to the percentage of IPOs that would qualify as "scams", or the funding volume directed to them - as IPOs are typically intermediated by underwriters that are liable for performing thorough "due diligence" on the issuing company and the overall conditions of the offering.
} 
The issue with ICOs is that it is difficult to draw solid conclusions on key metrics, such as performance or long-term survival rates, as there is not enough distance to perform such analysis. In addition, structural elements that are clearly defined in the context of IPOs - such as ownership, board, management and quotation on a centralised exchange - may be lacking in the case of ICOs, rendering a thorough evaluation more difficult to perform. ${ }^{95}$

Yet, the similarities that subsist between these two fundraising practices suggest that many of the factors used to conduct investigations about IPOs could also apply to ICOs. For instance, the prestige of board members ${ }^{96}$ or the legitimacy of top management ${ }^{97}$ are often regarded as powerful factors for enticing investors in the context of an IPO. Similar effects are to be expected in the context of an ICO, where the founding team and its advisors' reputation hold sway over the success of the token sale. Similarly, as the persistence of a founder's influence is considered to be an important risk mitigator in the context of IPOs, ${ }^{98}$ one can expect a somewhat similar effect in the context of ICOs, which are typically driven by the influence of the founding team over key programming and implementation decision. Thus, even though the elements of analysis are somewhat different, much of the research that has been conducted in the IPO context could potentially be applied to ICOs as well.

Besides the common risk of information asymmetries and the outright scams or embezzlement they may provoke, there are other risk factors common to both IPOs and ICOs, applicable to both issuers and investors.

From an investor's perspective, just as happens in the context of an IPO, there is also in the case of an ICO a clear risk that the invested capital may be lost, or that the expected returns on investment may not materialise. Dilution risks due to further rounds of capital raising - a common risk factor for IPOs - also exist in the context of some ICOs, most notably in the context of Security Token Offerings (STOs) or other token sales where tokens have voting and ownership rights associated to them. The lack of secondary market liquidity also exists in the context of both IPOs and ICOs and makes it difficult for investors to exit their position. Finally, with regard to informational components, a pricing risk might emerge when lack of, or excessively complex information makes it particularly challenging to establish the correct price of securities or tokens. There is also a risk related to the security of the information collected about investors - though recent regulations, such as GDPR in Europe, exist precisely to mitigate this risk.

More broadly, in addition to the standard operational risks that may occur either during the fundraising process or afterwards during the day-to-day operations, both IPOs and ICOs may encounter a principal-agent type of conflict, or a misalignment of interests

\footnotetext{
95 For instance, as previously discussed, some ICOs are not executed by a company or legal entity, but rather by a small team of individuals which lacks any official management or organisational structure.

96 ST Certo, "Influencing initial public offering investors with prestige: signaling with board structures" (2003) 28(3) Academy of Management Review 432.

97 BD Cohen and TJ Dean, "Information asymmetry and investor valuation of IPOs: Top management team legitimacy as a capital market signal” (2005) 26 Strategic Management Journal 683.

98 T Nelson, "The persistence of founder influence: Management, ownership, and performance effects at initial public offering” (2003) 24 Strategic Management Journal 707.
} 
between issuers and investors. Once the funds are raised, in fact, the individuals in charge may choose a different path from that which would be in the best interest of shareholders or contributors.

Lastly, there are various legal risks involved in these fundraising practices, not only due to the fact that prevailing regulation may evolve over time, ${ }^{99}$ but also related to the fact that investors might launch a lawsuit against token or securities issuers potentially even a class action lawsuit, most notably in the US. If class actions are known to happen against IPO issuers, ICOs are not exempt from this type of legal feud - as shown by the Tezos ICO's class action lawsuit. ${ }^{100}$

\section{b. Risk factors idiosyncratic to ICOs}

Though the ICO process has become more formalised over the years, it nonetheless remains much less structured than a traditional IPO's process, which is highly regulated and has been streamlined over decades of experience. ICOs also entail additional risks that are not generally found in an IPO. First and foremost, while an IPO is generally done as part of an "exit" strategy, an ICO represents more of an "entry" into the market, collecting funds in order to launch a new product or service that does not yet have any track record. Moreover, the lack of established intermediaries, and the lack of a clear regulatory framework for the various actors involved in an ICO, create additional uncertainties with regard to the ability for investors to cope with the complexity and uncertainty surrounding these new fundraising practices. At the same time, reliance on a "trustless" blockchain infrastructure means that, in the case of any problem or complaint, due to either a technical glitch or human error, there is no trusted authority with the power to intervene in order to remediate the problem - thereby leaving no delineated possibility of recourse. Finally, the blockchain ecosystem is subject to new types of systemic risk, related to the possibility of forking. We analyse each one of these idiosyncratic risks in the following subsections.

Different levels of maturity The maturity of a project is important in the context of financing as it translates into a particular degree of risk. Indeed, investments made at the seed or startup stage are usually riskier than investments in mature companies with stable cash flows. For instance, venture capital investing is "characterized by high variability in the outcomes of new ventures" whose "investment decisions remain hostage to unanticipated competitors, market shifts, and financial cycles". ${ }^{101}$

In the context of an IPO, it generally takes a few years before a company can go public. ${ }^{102}$ The company typically must demonstrate a proper (and stable) amount of revenues, which can only be achieved after a company has reached a certain level of

\footnotetext{
99 This is clearly more likely in the case of ICOs, for which regulation is still "in the making", than in the case of IPOs which are "mature" processes in most jurisdictions. Nonetheless, financial regulation may significantly evolve over time, as regulatory adjustments that took place over the last decade in the wake of the last financial crisis have shown.

100 Available at <restislaw.com/current-cases-investigations/tezos-initial-coin-offering/>.

101 JC Ruhnka and JE Young, "Some hypotheses about risk in venture capital investing” (1991) 6 Journal of Business Venturing 115-133.

102 For instance, the WilmerHale 2018 IPO report finds the median time to IPO for US companies to be 7.5 years: $<$ www.wilmerhale.com/en/insights/publications/2018-ipo-report $>$.
} 
maturity. There are hard and soft requirements for an IPO, which might vary with the listing requirements of the exchange involved and the jurisdiction at hand. For instance, some jurisdictions might require a minimum number of years of operations with audited accounts as a prerequisite to an IPO. ${ }^{103}$ In addition, investment banks acting as underwriters will tend to select IPO candidates that appear solid and likely to perform well in the future. While investment banks competing for underwriting business may be tempted to lower their requirements for winning over the leading role, if they want to be around in the long run, they will have to subject the issuing companies to a tight scrutiny in order to maintain their reputation. Indeed, an underwriter associated with a series of poorly performing IPOs will lose its credibility on the market, and - in the worst case scenario - underwriters may even be sued by investors. $^{104}$

Most ICOs lay at the opposite end of the spectrum. In many cases, the project for which tokens are offered to the public are just outlined in a white paper and have no practical implementation. As claimed by some ICO critics, some projects were able to raise substantial amounts of money (more than US $\$ 100 \mathrm{~m}$ ) with no prototype, just on the promise of future developments. ${ }^{105}$ To some extent, the fact that some ICOs managed to raise such a large amount of funds almost out of thin air is illustrative of an irrational exuberance that is reminiscent of the height of the Internet bubble. Though further research might be needed to substantiate this point, we suggest that this similarity between today's ICOs and dot-coms IPOs is likely derived from a common root of: (i) an emerging technology with a promising potential but still too few realworld applications; and (ii) the perception that first-mover advantage is critical in the face of rapidly developing markets.

Risks of disintermediation The issue of disintermediation is, in our view, one of the cornerstones of a proper ICO risk analysis. Indeed, one key differentiating factor between an IPO and an ICO is the level of intermediation - or rather, the lack thereof in the context of an ICO - and the absence of underwriters that are typically present in the context of an IPO. Thus, by bypassing many of the specialised intermediaries, blockchain technology induces the loss of the risk-mitigating functions these intermediaries had been implicitly fulfilling.

As we have previously seen, public offerings are bound to create information asymmetries between issuers and investors, because the former have more information on how the raised funds will be used. Furthermore, even if we assumed no information asymmetries between issuers and investors, the "limits of human cognitive capacity for discovering alternatives, computing their consequences under certainty or uncertainty, and making comparisons among them", as underlined by

\footnotetext{
103 In the US companies are "generally required to disclose selected financial data for the prior five years" unless it is an "emerging growth company" - this disclosure can be limited to the prior two years - or a "smaller reporting companies" - this requirement is waived. See <www.sec.gov/files/ipo-investorbulletin.pdf $>$, p 3.

104 Drake and Vetsuypens examine 93 IPOs by issuers who were subsequently sued under provisions of the 1933 and/ or 1934 Securities Acts in the period 1969 to 1990: P Drake and M Vetsuypens, "IPO Underpricing and Insurance against Legal Liability" (1993) 22 Financial Management 64.

105 See <www.coindesk.com/ethereum-icos-youre-wrong/>.
} 
Simon's work on bounded rationality and rational choice, ${ }^{106}$ highlight how difficult it is for investors to make accurate predictions as to the future development of the project, let alone to properly perceive and assess the risks associated with an ICO. Precisely, Simon reminds us that one of the common responses for dealing with bounded rationality and "coping with the limits of a man's abilities to comprehend and compute in the face of complexity and uncertainty"107 is to "divide up the decision-making task among many specialists, coordinating their work by means of a structure of communications and authority relations". ${ }^{108}$ This is a task which, in the context of an IPO, is generally assumed by underwriters and registered broker-dealers - two important types of intermediaries which have not been transposed in the context of ICOs.

This absence of these intermediaries is understandable given the structural difference of these two fundraising practices. An IPO is typically done by companies with a certain level of maturity and established institutional relationships, while an ICO is usually undertaken by early-stage projects steered by a team of geeks wishing to rally a community of enthusiastic peers to their cause. If the former has been soaked in a world of traditional institutions accustomed to hierarchy and trusted third parties, the latter precisely aims to disrupt traditional financing channels perceived as entangled in a web of superfluous institutional intermediaries.

In the early days of ICOs, only members of the blockchain community were interested in participating into a token sale. These early adopters generally had a sufficient level of knowledge to evaluate the quality of the projects, as people of the same "breed" were evaluating each other's work. But as more and more followers started to pile in sometimes just motivated by greed and expectations of profits - the knowledge gap between token issuers and ICO subscribers began to broaden. It is precisely in this transitory phase, characterised by feisty exuberance and herd-like mimetic behaviour, that the risk of scams and speculative bubbles is at its highest.

As soon as ICOs became more mainstream and started to draw large amounts of funding, they progressively started to convene similar types of actors as those involved in IPOs. As popular and institutional interest grows - with institutional investors searching for new investment opportunities or industrial companies looking to leverage the technology - a new market for specialised advice emerged, paving the way for new intermediaries, similar to those we encounter in the context of IPOs. For instance, since 2017, a series of technology-oriented boutique investment banks or auditing firms have started to provide ICO advisory services. ${ }^{109}$

Transferring trusted third-party risk to a "trustless" technology As a starting point to think about disintermediation in the context of blockchain technology, it is interesting to look at the principles that have driven the design of the first blockchain, Bitcoin. In the Bitcoin white paper, Satoshi Nakamoto describes the goal of disintermediating financial institutions by providing "a purely peer-to-peer version of electronic cash [that] would

\footnotetext{
106 HA Simon, “A Behavioral Model of Rational Choice” (1955) 69(1) The Quarterly Journal of Economics 99-118. 107 ibid.

108 See Simon's 1978 Nobel Memorial Lecture titled "Rational Decision-making in Business Organizations”, <core. ac.uk/download/pdf/6322096.pdf >.

109 For instance, PWC in Zurich offers support and advisory services for ICOs. See <www.pwc.ch/en/industrysectors/financial-services/fs-regulations/ico.html>.
} 
1308

1309

1310

1311

1312

1313

1314

1315

1316

1317

1318

1319

1320

1321

1322

1323

1324

1325

1326

1327

1328

1329

1330

1331

1332

1333

1334

1335

1336

1337

1338

1339

1340

1341

allow online payments to be sent directly from one party to another without going through a financial institution". ${ }^{110}$ As an alternative to traditional payment systems centered around a trusted authority, Bitcoin offers a protocol whereby "any two willing parties [can] transact directly with each other without the need for [any] trusted third party". ${ }^{111}$ This shift from a centralised paradigm to a distributed peer-to-peer system is supposed to address some of the security concerns that some computer security experts, such as Szabo, have had with trusted third parties - described as a "nice sounding synonym for a wide-open security hole that a designer chooses to overlook". ${ }^{112}$

Thus, a blockchain is meant to shift the reliance on a single trusted authority to a decentralised network of peers, in order to achieve a higher degree of technological guarantees. ${ }^{113}$ Because all active nodes in the network have a local copy of the blockchain, it is impossible to tamper with the contents of this decentralised database without going unnoticed (unlike the case of a centralised database which can be tampered by a centralised operator, without users noticing). As a result, the risk of censorship or self-dealing on the part of a trusted third party becomes moot as the operations of the network depends, only and exclusively, on the rules encoded within the blockchain protocol - which are collectively enforced by all network participants. Trust in an institution (eg a bank) or in a certifier (eg a notary) is replaced by distributed trust in a set of code-based rules, which are deemed impossible to bypass or circumvent. $^{114}$

At the same time, however, distributed governance brings about new risks. For instance, in the case of Bitcoin, there is no possible recourse for reverting a fraudulent transaction resulting from the theft of a private key (whereas it is always possible to file a complaint with one's bank in the case of a fraud). Furthermore, the consensus mechanism of public and permissionless blockchains like Bitcoin can be potentially "co-opted" by a few powerful actors with significant computational power. Indeed, both in the case of Bitcoin and Ethereum, today, a small number of mining pools control more than $50 \%$ of the network's total hashing power. Hence, if they were to collude, they would have the opportunity to censor certain transactions, and potentially even to tamper with the history of transactions. ${ }^{115}$

New types of systemic risk When it comes to traditional finance, systemic risk has been defined by G-20 finance ministers and central bank governors as a "risk of disruption to financial services that is (i) caused by an impairment of all or parts of the financial system and (ii) has the potential to have serious negative consequences

110 S Nakamoto, "Bitcoin: A Peer-to-Peer Electronic Cash System" (2008) < bitcoin.org/bitcoin.pdf> (last accessed 3 July 2019).

111 ibid.

112 N Szabo, "Proplets - Devices for Controlling Property" (2001) <www.fon.hum.uva.nl/rob/Courses/ InformationInSpeech/CDROM/Literature/LOTwinterschool2006/szabo.best.vwh.net/proplets.html > (last accessed 4 July 2019).

113 A Wright and P De Filippi, "Decentralized blockchain technology and the rise of lex cryptographia" < papers.ssrn. com/sol3/papers.cfm?abstract_id=2580664> (last accessed 4 July 2019).

114 P De Filippi and R Mauro, "Ethereum: the decentralised platform that might displace today's institution" (2014) 25(08) Internet Policy Review.

115 These and other issues related to blockchain governance have been analysed more in depth in the following report: P De Filippi and G McMullen, "Governance of blockchain systems: governance of and by the infrastructure" (2019) COALA \& Blockchain Research Institute Big Idea Whitepaper. 
for the real economy". ${ }^{116}$ In that sense, it is clear that unless crypto-assets become so prevalent that they could cause such a disruption, they currently represent little systemic risk to the overall financial architecture. In fact, in February 2018, at a time where the market capitalisation of digital currencies was roughly twice what it is at the time of writing, the ECB president, Mario Draghi, stated that the ECB was "not observing a systemically relevant holding of digital currencies by supervised institutions" but added that the ECB needed to keep an eye on crypto-assets as new risks could arise, such as those due to the introduction of Bitcoin futures contracts on US exchanges. ${ }^{117}$

This being said, a different type of systemic risk may emerge in the context of blockchain-based systems: the risk of disruption to the overall ecosystem supported by a given blockchain. One clear instance of this type of risk would be an undetected flaw in the underlying protocol of a particular blockchain network. An example of such problem already happened on Ethereum, as a bug in the code (aka a smart contract) deployed on the blockchain required to patch the Ethereum protocol, resulting in a "hard fork" 118 of the underlying blockchain. ${ }^{119}$

This highlights the existence of alternative types of systemic risk, such as the risk of forking, which the Bank of International Settlements defined as "symptomatic of a fundamental shortcoming: the fragility of the decentralised consensus involved in updating the ledger and, with it, of the underlying trust in the cryptocurrency". ${ }^{120}$ While, in theory, no one can force network participants to adopt a new blockchain protocol, given the network effects at play within existing blockchain network, there is a strong incentive for everyone to agree on a particular version of the protocol. Hence, even though a blockchain ultimately relies on distributed consensus, in practice, not all participants are on the same footing: major exchanges and blockchain explorers, as well as core developers and opinion leaders weigh heavily on how the protocol of a particular blockchain-based network might evolve over time. If forking could be compared to company splitting, an important difference between the two is that company splitting is typically planned and anticipated, while forking usually results from an unexpected bug that took the overall blockchain community by surprise - as was the case with TheDAO's issue in 2016 and the subsequent forking it triggered on Ethereum. ${ }^{121}$

\footnotetext{
116 Guidance to Assess the Systemic Importance of Financial Institutions, Markets and Instruments: Initial Considerations. Report to the G-20 Finance Ministers and Central Bank Governors. Staff of the International Monetary Fund and the Bank for International Settlements, and the Secretariat of the Financial Stability Board (October 2009).

117 See <www.bloomberg.com/news/articles/2018-02-05/draghi-says-ecb-studying-digital-currency-risks-forbanks $>$.

118 Forking happens whenever a fraction of an existing blockchain community decides to opt out of the existing blockchain protocol and adopt a new set of rules - which, in the case of a "hard fork", are incompatible with the previous rules.

119 W Reijers et al "Now the Code runs itself: On-chain and Off-chain governance of blockchain technology" (2018) 37(17) TOPOI: International Review of Philosophy.

120 See the Bank of International Settlements (BIS) Annual Report 2018 p 102, <www.bis.org/publ/arpdf/ar2018e. pdf $>$.

121 Q DuPont, 'Experiments in Algorithmic Governance: A history and ethnography of 'The DAO,' a failed Decentralized Autonomous Organization" in Bitcoin and Beyond (Routledge).
} 
1375

ICOs provide many new opportunities for blockchain-based projects and initiatives to raise funds that they may be unable to raise in more traditional capital markets settings. These new fundraising practices are, however, not devoid of any risks. Just as crowdfunding did in the past, ICOs raise important questions with respect to financial regulation. First of all, because the nature of ICOs can vary a great deal, it is not always easy to pin them down unto an existing framework. Secondly, monitoring the course of an ICO may require technical knowledge that is not always available to existing regulatory bodies. Finally, the absence of a strict regulatory framework to control and supervise these new fundraising practices opens up the door for all sorts of abuses and scams - potentially posing a serious threat for investors.

Although they rely on a new technological infrastructure, ICOs share many similarities with the various IPOs and crowdfunding endeavours that have become increasingly popular after the advent of the Internet. In the US, Rodrigues has shown that many ICOs are likely to fit within the scope of existing security laws, including the various exemptions they comprise. ${ }^{122}$ In other jurisdictions, such as the EU, although they come with a more specific regulatory framework regarding what may or may not qualify as a security, ${ }^{123}$ it is important to engage in a careful scrutiny of the alternatives they provide before trying to "reinvent the wheel", ${ }^{124}$ to put it in a metaphorical way.

In particular, given the risks involved with these fundraising practices, especially in the case of equity and debt-based crowdfunding, a series of regulations were put in place in order to lower the risk for investors willing to contribute money to such initiatives. Because IPOs generally involve substantial amounts of money, they give rise to significant risks for investors, which can only be mitigated by imposing stringent regulatory constraints both on the security issuers and on the intermediaries through which these securities are traded. With crowdfunding, risks are reduced by introducing additional constraints concerning the amount of funds that can be raised, and the amount that can be contributed by each individual investor. Hence, the degree of regulatory constraints that fall on both the issuers and intermediaries involved with these fundraising practices can be significantly lowered as well.

The situation is slightly different in the case of ICOs. Many token issuers are not satisfied with the limitations imposed by crowdfunding regulations - in particular with regard to limitations on the amount of funds that can be raised or invested, and the obligation to operate via a registered intermediary. Because they need (or aspire) to raise more funds than is permitted under the crowdfunding exemption, token holders have attempted to design their token sales to be as far removed as possible from the traditional IPO or equity crowdfunding models, and closer to the model of reward-based crowdfunding, which is not subject to securities law. In doing so, token

122 U Rodrigues, "Semi-Public Offerings? Pushing the Boundaries of Securities Law" (2018) Paper No 2018-30 Research Paper Series. School of Law, University of Georgia.

123 For an overview of relevant laws and regulations across jurisdictions, the reader may consult De Filippi et al, supra, note 70 .

124 Hacker and Thomale, supra, note 20. 
issuers are trying to dodge any form of securities-like regulation, without providing any type of remedy to mitigate risks. Therefore, even if they share many similarities in both their structure and function, investing into an ICO generally represents a riskier endeavour than investing into a more traditional crowdfunding project, or even a traditional IPO - whose risks are mitigated via regulatory constraints.

According to a principle-based regulatory approach, to the extent that the risk profile of an ICO is higher than that of other regulated fundraising activities - because of the immaturity of the project, and the additional risks related to disintermediation and the technical specificities of blockchain-based solutions - token issuers will need to abide by a variety of rules and regulations designed to protect investors by reducing information asymmetries, promoting market stability, and ultimately decreasing the likelihood of market manipulation and systemic risk. Indeed, if the risks are actually higher, one might even be tempted to claim that an ICO should actually be regulated in a more stringent way than traditional IPOs, in order to compensate for the higher risks it entails.

Yet, our claim is that there is an alternative approach, that might contribute to reducing the risks surrounding an ICO, without stifling the opportunities for innovation in the blockchain space due to stringent regulatory constraints. We contend that it is possible to introduce additional measures to mitigate the risk factors of an ICO, not only by means of a regulatory intervention but also (or rather) by means of technological design.

This brings us to yet another application of the doctrine of functional equivalence, related to the extent to which a particular technological arrangement could be held to be functionally equivalent to a regulatory provision - ie the extent to which it can act as a regulatory technology that contributes to achieving a particular policy or regulatory objective. ${ }^{125}$

\section{Blockchain technology as regulatory technology}

Just as in the case of e-commerce, establishing functional equivalence in the context of an ICO also requires understanding the underlying reasons and regulatory objectives of specific legal provisions, in order to assess whether they can be fulfilled by technical means. In other words, the question is whether specific technological features, enabled by blockchain technology, could satisfy some of the requirements of existing securities law by reducing some of the risks that the regulations are meant to address.

The particularity of blockchain technologies is that, as opposed to traditional means of security issuance, which are ultimately based on contractual agreements and paper-based formalities, ICOs are done via a technical infrastructure which is inherently "programmable" and can therefore incorporate a variety of technical features that could help achieve some of the regulatory objectives enshrined in specific provisions of security laws. ${ }^{126}$ Blockchain technology can thus provide an automated means of

\footnotetext{
125 P De Filippi and S Hassan "Blockchain technology as a regulatory technology: From code is law to law is code" (2018) arXiv preprint < arXiv:1801.02507>.

126 P De Filippi and A Wright, Blockchain and the Law: The Rule of Code (Harvard University Press 2018).
} 
making sure that the public offering process complies with the principles described above, and that the process incorporates all features and functionalities required in existing regulations to protect token issuers and investors from potential risks. ${ }^{127}$

Blockchains and smart contracts make it possible to implement, at reasonable costs, technical features that were difficult to implement in a traditional centralised setting. For instance, in order to protect investors, the smart contract governing an ICO could incorporate a series of "technical guarantees" through a series of technological constraints designed to reduce the degree of risk that would otherwise need to be incurred by investors.

In such case, it would seem fair to assume that this particular token sale could benefit from a lower regulatory burden, because risk has been mitigated by technological (rather than regulatory) constraints. Even in the case of an STO, the issuance of security tokens via a blockchain-based infrastructure that would provide additional guarantees to investors, particularly as to the way in which raised funds can be used, could benefit from a more lenient regulatory framework than traditional IPOs, because - in spite of their functional equivalence - they do not raise the same typology of risks.

Thanks to smart contracts, ICOs bear the potential of providing more refined control mechanisms over the collected funds, while lowering compliance costs and decreasing investors' risks. For instance, if a public company with quarterly filings were to announce bad results, individual investors would typically have to bear the full impact of this bad news. A properly designed ICO smart contract could mitigate some of these risks. Instead of giving a blank cheque to the company, and seeing later what comes out of it at every public filing, the ICO smart contract could lock funds into an escrow smart contract and gradually make the investors' funds available to the fundraising according to a predefined roadmap, controlled by the achievement of sequential milestones. This would make it possible for investors who purchased tokens during the token sale to redeem these tokens in order to recoup all or part of their investment, at specific time intervals, if they considered that the project did not meet some of the milestones that it had committed to, ${ }^{128}$ or if they collectively believed the funds were not properly used, but not simply because they no longer wanted to support the project. In this way, both the fundraising team and the investors can rest assured that they will not be disappointed: if the team does not achieve its deliverables, investors will be able to retract their investment, but, as long as the milestones are achieved, the team will be able to rely on a steady stream of payments, without having to engage in additional fundraising rounds. ${ }^{129}$

Indeed, it was already possible to do this before with managed escrow accounts (a concept that precedes the digital age), and corporate entities raising public money in an IPO have always been held accountable for how they use the proceeds (for

\footnotetext{
127 Some of these solutions have been highlighted in a previous report written by the same authors: Wang et al, supra, note 71 .

128 Note, however, that the fact of keeping the money on behalf of the investors, at least until the relevant milestones have been fulfilled, might require the token issuers to acquire a banking licence.

129 Of course, these safeguard measures comes at a cost. Locking funds into a smart contract means that neither the fundraising team, nor the investors, will be able to collect rent from the escrowed funds, unless a new intermediary is introduced into the picture, with a view to manage these funds.
} 
instance, through the investigations of research analysts). Yet, smart contracts can provide greater granularity to this oversight process, by both automating and simplifying it. For example, in order to protect token issuers, ICOs could temporarily disable the "send function" associated with the tokens being sold, thereby locking these tokens for a specific period of time, in order to ensure that the management team and the investors who purchase these tokens are actually aligned with the longterm success of the projects, and will be unable to engage into speculative practices such as "pump and dump". This seemingly innocuous feature goes a long way and may have profound implications on financial markets and their regulation in the long term.

In the longer term, one could also imagine that a multi-featured token will act as a smart security, ${ }^{130}$ eg one where the decision to convert a debt-like feature into an equity-like feature can be done automatically (ie this would be equivalent to having convertible bonds with automated conversion features, or American options with embedded automated exercise patterns). Although the idea of a smart security is still prospective and has no real incarnation yet in financial markets, we suspect that ICOs, smart contracts, and smart securities, are likely to have a deep impact on securities laws in the future.

Finally, while securities law requires extensive formalities and reporting obligations, as a means of ensuring that the money that has been invested in the project is being used properly, the transparency inherent in blockchain technology, along with the programmability of the underlying technological infrastructure, makes it possible to achieve real-time auditing and automatic reporting. This decreases the need for parties to engage in traditional audits and reporting, which are generally cost prohibitive for many small players. ${ }^{131}$ Alternatively, the management team could be required to record, on a blockchain, every expense, digital currency transaction or exchange of digital currency into fiat currency, with the specific line of business that the transaction is associated with - thereby facilitating the work of auditors and inspectors through the creation of a transparent, tamper-resistant and non-repudiable audit trail.

Another possibility is to rely on specific technological arrangements in order to ensure that the tokens issued through an ICO do not fall within the qualification of an investment contract, and therefore do not need to comply with securities law. This could be achieved, for instance, by limiting the ICO tokens' speculative potential. A smart contract could, indeed, be designed to offer a constant supply of tokens at a particular price, regardless of the market price. Hence, if the market price were lower than that of the smart contract, people would purchase tokens on the secondary market. But if the market price were to become higher, people would then have the opportunity to purchase tokens directly from the smart contract - thereby increasing the overall token supply, and thus progressively reducing the market price.

\footnotetext{
130 De Filippi and Wright, supra, note 126.

131 However, this only applies to the extent that the management team actually relies on the underlying blockchain as a payment system, which is unlikely to be the case, as least for the coming years.
} 
Such a utility token model that does not come with a fixed quantity of tokens would contribute to drastically reducing the speculative dynamics of the token sale, which would therefore be more likely to fall within the category of a pre-sale contract (being functionally equivalent to reward-based crowdfunding), and potentially escape from the scope of traditional securities regulations. Of course, a corollary drawback would be that reducing speculative opportunities over the token's value might also discourage some of the investors in contributing to the ICO.

Ultimately, it is up to the fundraising team to decide what is the most effective strategy to follow. If the team only needs a few hundred thousand dollars, they can fit within the crowdfunding exemption. Otherwise, they will have to choose between either complying with the broad range of formalities and regulatory constraints imposed by IPO regulations, or rather submit themselves (and the investors) to specific technological and economic constraints, automatically enforced by the underlying blockchain infrastructure.

Of course, given the relative immaturity of blockchain technologies, it is still difficult, for the time being, to understand precisely which technological features could be regarded as being functionally equivalent to specific provisions of securities law, especially with regard to systemic risk and investor protection. Market players have just begun to experiment with these new technologies, and more time is required to ascertain - from an empirical perspective - whether a particular feature could, indeed, satisfy the same regulatory objectives enshrined into securities laws.

\section{Private regulation and standardisation}

One of the main issues with the regulation of ICOs is that it is still too early for regulators to establish rules that require token issuers to abide by certain principles or to implement specific technical guarantees into their ICOs models. Indeed, given the rapid pace of technological progress, it has become increasingly difficult for governments and regulatory authorities to keep pace with these new technological developments. The lack of expertise with regard to the technical aspects of blockchain technologies further complicates the task of coming up with proper regulations that may accommodate these new technologies. As a result, instead of trying to elaborate a topdown regulatory mechanism for ICOs, it might be more appropriate for governments to delegate the task to the private sector, eg by devolving some of their regulatory functions to large international standard-setting organisations.

This growing trend towards private regulation has already been observable for a while. As described by Tim Bühte and Walter Mattli in their book The New Global Rulers, coregulation via standard-setting organisations is becoming an appealing answer to governance issues in fast moving and complex technology driven areas. ${ }^{132}$ While it is still early to think about the establishment of standards for ICOs, we are already seeing the development of informal practices within the blockchain ecosystem, as

132 T Büthe and W Mattli, The New Global Rulers: The Privatization of Regulation in the World Economy (Princeton University Press 2011). 
many companies proposing ICOs are trying to converge towards a set of best practices that are more in line with the basic concerns of regulators.

This point was addressed in a recent report by Smith \& Crown, ${ }^{133}$ where it was suggested that the blockchain community co-develop a set of best practices or guidelines for token issuers, in order to avoid an excessively strict regulatory response from regulators - increasingly concerned with the growing amounts of fraudulent or illegitimate token sales that could be launched every day. Most importantly, these best practices could contribute to helping regulators understand how the technical guarantees enabled by blockchain technologies could not only facilitate these new fundraising practices, but also to a large extent ensure that investors' interests and consumer protection regulations are respected. This opens the possibility of translating existing regulatory aspects into technological blocks, making sure that existing legal requirements are enforced through technological checks and balances.

As time goes by, and as outcomes can be more clearly and empirically assessed, standard setting organisations could eventually incorporate these best practices and technological guarantees into more structured and standardised frameworks. While most of these standard frameworks merely operate on a voluntary (opt in) basis, governments could nonetheless provide incentives for the industry to adopt these standards, so as to ensure a broader harmonisation and more widespread adoption of these practices.

In line with the principle of functional equivalence, governments could, for instance, recognise some of these technical standards as providing the same functions as existing laws or regulations. This particular interpretation of "functional equivalence" is important as it would enable companies eager to engage into an ICO to check with regulators that their offerings comply with existing regulations. If their technical solutions qualify as being functionally equivalent to specific rules or regulations, parties could potentially benefit from a more lenient regulatory framework, in that they may no longer be required to comply with all of the requirements needed to register securities. In particular, parties who agree to implement these technical guarantees into their ICO models could forgo some of the formalities and reporting obligations required under the law, whose functions can more easily be fulfilled via technological means. Indeed, so long as the underlying regulatory objectives are satisfied, it is largely irrelevant whether these are satisfied through technological or other means. What matters is that, in the end, token sales are done in such a way as to comply with the law, by reducing the degree of risks that these new fundraising practices entail. By recognising the functional equivalence of specific technical guarantees, governments could ultimately strike a balance between the need to protect investors and enabling many new industries to develop.

\footnotetext{
133 Smith \& Crown, Overview and Analysis of ICO Regulatory Developments (20 September 2017), available at $<$ www.smithandcrown.com/overview-analysis-ico-regulatory-developments/>.
} 


\section{Conclusion AND FURTHER RESEARCH}

1609

1610

1611

1612

1613

1614

1615

1616

1617

1618

1619

1620

1621

1622

1623

1624

1625

1626

1627

1628

1629

1630

1631

1632

1633

1634

1635

1636

1637

1638

1639

1640

At the time of writing, the ICO wave has settled down and we do not know yet if it will rise back as a tsunami or completely dry out as a short-lived fountain of enthusiastic technological exuberance. Indeed, the ICO environment seems to have matured a lot since the heydays of 2017 - so much so that at the end of 2018, technology pundits were reflecting over whether the so-called "crypto-winter" was there to stay. ${ }^{134}$ Clearly, the way regulators around the world will tackle this phenomenon will influence the outcome of this question.

As we have conveyed in this paper, ICO tokens do not always, nor necessarily qualify as investment contracts or securities. Indeed, more often than not, these tokens assume a more hybrid nature, where the investment component is generally significant, but not the only one. Yet, while the motivations that have driven the vast majority of ICOs were not only financial, the ability that ICOs provide to raise funds in a quick and flexible manner, even at a very early stage (especially in the years from 2016 to 2018) has been a key driver of experimentation in the blockchain space.

The ICO environment has been evolving rapidly over the last years, and the initial success of early ICOs quickly drew the attention of a new crowd of opportunistic entrepreneurs and speculators with little knowledge of blockchain technology. As is often the case with new technologies, as the technology matures, it draws all sorts of interests, ranging from individual and commercial experimentation to broad institutional acceptance and speculation. With regard to the latter, Keynes' "animal spirits" 135 are never far away, lurking around the corner and ready to accelerate a trend into a thoughtless bubble. This has happened before: with the tulip bulbs in 1637, the stocks of the South Sea Company in 1720, and with the subprime mortgage-backed securities in 2005-2008. We should be wary - to paraphrase a now famous formula - of thinking that this time, "it will be different". ${ }^{136}$

In this respect, ICOs might remind us of one of the key reasons why financial regulations are needed: to protect consumers from risks derived from irrational exuberance and unscrupulous scams. ${ }^{137}$ The ICO phenomenon, initially geared only towards geeks and other technophiles, rapidly spread and turned into a more pervasive craze. ${ }^{138}$ As this happened, information asymmetries between issuers and new participants widened, highlighting the role and reinforcing the need for specialised intermediaries to mitigate this growing information gap.

\footnotetext{
134 See <www.coindesk.com/the-crypto-winter-wasnt-the-real-story-of-2018-and-it-wont-be-for-2019-either>.

135 In his 1936 book on The General Theory of Employment, Interest and Money, Keynes underlines how "animal spirits" - which he describes as "a spontaneous urge to action rather than inaction, and not as the outcome of a weighted average of quantitative benefits multiplied by quantitative probabilities" - drive and influence human behaviour.

136 This expression refers to the best-selling book by C Reinhart and K Rogoff published in 2009, This Time Is Different - Eight Centuries of Financial Folly that reminds us that the basics of economics do not really change, no matter what fantasies people come to believe, and that it is surprising anyone ever believed that the subprime-driven housing bubble of 2005-2008 was to be treated any differently than past housing bubbles.

137 DA Zetzsche, “The ICO Gold Rush: It's a Scam, It's a Bubble, It's a Super Challenge for Regulators” (2017) University of Luxembourg Law Working Paper (11) pp 17-83.

138 Y Chen, "Blockchain tokens and the potential democratization of entrepreneurship and innovation" (2018) 61(4) Business Horizons 567.
} 
What should regulators' response be? ICOs raise the same fundamental questions that have haunted regulators and policy makers for decades when faced with new technological innovations. In the face of a new technology with a strong potential that is not yet clearly understood, an appropriate regulatory response should try to mitigate the risks, without unduly restraining the opportunities for innovation. Indeed, if over-regulation risks stifling creativity, eventually driving entrepreneurs to a more lenient or accommodating jurisdiction, under-regulation may foster scams and other setbacks that may damage the public perception of this new technology, ultimately hurting its potential.

Though it is too early, at the time of writing, to come to a conclusion on the future developments of ICOs, as the stakes get higher and regulators become more acquainted with these new fundraising practices, many ICOs might end up being characterised as a regulated activity falling under the framework of traditional securities law. ICOs might thus have to restructure themselves, with the introduction of new intermediaries acting as counsellors or underwriters. There is already abundant academic literature on the role of underwriters and syndicates in the price discovery and valuation processes of an IPO, ${ }^{139}$ and we might expect similar analyses to develop in the case of ICOs.

But ICOs also bring to the forefront other ethical or philosophical questions that regulators have to deal with. For instance, to what extent should investors/participants be protected from their own greed and animal instincts? Or, more generally, is a laissez-faire approach based on market forces alone preferable to any kind of regulatory interference? If the last financial crisis seems to have given a clear answer to this conundrum, the ICO market is still relatively recent and is not yet considered to constitute a systemic risk. That is why we consider that a flexible principle-based regulatory approach, drawing from the concept of functional equivalence, should be more appropriate at this stage. More precisely, by comparing the risks raised by ICOs, IPOs and equity crowdfunding, we advocate for an interpretation of functional equivalence not only based on the function and legal qualification of these new fundraising practices, but also resting on an in-depth analysis of risks inherent in the contextual settings within which these practices are undertaken.

In our view, the most interesting aspect of blockchain technology in the context of financial regulation is precisely how it could be used to improve it. Indeed, if - as we have described before - the principle of functional equivalence was originally intended as a means to incorporate electronic transactions into the context of traditional contract law, the same principle could easily be used to incorporate ICOs into the context of traditional securities law. Yet, as happened with digital technologies in the context of e-commerce, the technological advances brought about by blockchain technologies may turn out to be great tools for securing the enforcement of securities laws and regulations, and, more broadly, for improving the operations of financial markets.

So far, most of the focus in the financial sector has been on the use of regulatory technology ("regtech") to support regulatory reporting and compliance. In our view,

\footnotetext{
139 See for instance SA Corwin and P Schultz, "The role of IPO underwriting syndicates: Pricing, information production, and underwriter competition" (2005) 60(1) The Journal of Finance 443-486.
} 
1683

1684

1685

1686

1687

1688

1689

1690

1691

1692

1693

1694

1695

1696

1697

1698

1699

1700

1701

1702

1703

1704

blockchain technology can do more than that. By incorporating technological guarantees into the very fabric on an ICO, token issuers could reduce the level of risks that these fundraising practices present for investors, and financial markets more generally thereby reducing the need to comply with the stringent rules and regulations that currently affect the majority of public offerings.

One crucial question that remains an important area of further research is whether blockchain technology might eventually result in an evolution of existing financial regulations, or even lead to the creation of new laws. Just as the development of information technology forced the evolution of privacy and data protection regulations in the US and Europe (with the General Data Protection Regulation being the latest example), we might expect securities laws to evolve along with the broader adoption and integration of blockchain technology and smart contracts into the global financial fabric. To some degree, we are already seeing the first glimmers of this trend, as financial regulators around the world are beginning to regulate ICOs.

Yet, ICOs may just be the tip of the iceberg. For instance, if distributed ledger technology holds the promise of instantaneous settlement - thereby making central counterparty clearing houses (CCPs) obsolete - they might end up transforming the whole post-trade regulatory environment, which is intertwined with the existing financial infrastructure. And if blockchains and smart contracts were to transform the very nature of financial securities, their potential for disrupting existing securities regulations in the long term would be further enhanced. Regardless of how the law will evolve, we have no doubt that the next five years will be particularly interesting for all involved stakeholders.

\section{Appendix: existing regulatory frameworks for ICOs}

In this appendix, we reflect upon the basic precepts that have so far guided the establishment of the regulations across various jurisdictions - keeping a particularly watchful eye on EU and US environments.

Designing a proper regulatory framework is particularly important in the context of ICOs, where the lack of international harmonisation might result in significant opportunities for regulatory arbitrage. Competition between jurisdictions to provide the best suited regulatory environment for this promising innovation might lead some jurisdictions to focus more on creating an efficient, flexible, and accommodating regulatory framework for innovators, with less attention put on the core objectives of combatting fraud, and protecting the interests of all parties involved - subscribers and issuers alike.

In light of these regulatory approaches, it appears as though the similarities between ICOs and IPOs have leaned towards assimilating ICOs to traditional securities offering - although some jurisdictions have established a more lightweight set of rules for ICOs, in particular circumstances.

Stepping back and looking at the ICO trends since their inception, it is now clear that many ICOs in the 2014-2016 period did not account for securities regulation. While some simply hoped to remain under the regulator's radar, others considered that hybrid nature and original status of ICO tokens disqualified them from being regarded as investment securities.

Although early token sales were done in the shadows of the law, as the amount of investments raised by ICOs started to grow, reaching several hundreds of millions of dollars for some projects, it eventually caught the attention of regulators, which eventually intervened. Both TheDAO and Munchee episodes (described in the article) emphasised the regulatory risk attached to a jurisdiction where the regulator has not yet clarified its stance over how this innovation should be treated. ${ }^{140}$

140 Hopefully, in both of these instances, the regulatory damage was limited: in the former case, TheDAO had ceased to exist by the time the SEC published its investigative report; in the latter case, Munchee "consented to the SEC's ceaseand-desist order without admitting or denying [its] findings". 
The growing need for regulation was also marked by the fact that, as opposed to the early projects which had a strong team and a large community behind them, in 2017 and 2018 more and more projects were launching ICOs with nothing more than a website and a white paper. Regardless of the quality of their ideas, these projects were generally driven by a small team of people with little to no managerial experience, who were mostly interested in exploring new ways to raise money. These teams spent a lot of money in promoting their ICO - ie communicating about their upcoming token launch, in order to create hype around the tokens and therefore get a maximum number of investors on board - sometimes spending up to several million dollars for their campaign, rather than focusing on the development of the project itself.

To complicate things further, there was often little transparency concerning the way in which these projects were operated and by whom, what their corporate structure was (if any), who controlled the funds and how these funds were to be spent over time. There were also many uncertainties concerning the scope of initial pre-sales, in the form of private placements with strategic investors, often with considerable discounts to these early investors, whose identities were generally not known to the public.

This led several regulatory authorities across the globe to raise concerns about the need to integrate ICOs within existing regulatory frameworks, or perhaps even create new regulations specifically designed to address these concerns. Given the strong similarities between ICOs and IPOs or equity crowdfunding - as we hope to have shown - most of the reactions thus far came from securities regulators, eager to expand the scope of security regulations over these new fundraising practices. Despite the best efforts and claims made by many token issuers, who often tried to elaborate novel utility models for their tokens in order to bring them as far as possible from securities, it has often been the case that - in practice - these tokens have actually been used and purchased as securities (ie investment contracts).

Accordingly, many regulatory authorities from different jurisdictions have been active in trying to figure out the best way to regulate these token sales, in order to ensure compliance with security laws (especially the rules concerning consumer and investor protection) without unduly hindering innovation. From the delivery of preliminary warnings, to the issuance of statements or reports, and, in some cases, the enactment of new rules and regulations, a variety of regulatory interventions have taken place around the world, and are still in the making in some parts. These interventions have often reflected different - and discrepant - approaches, thereby creating a significant lack of harmonisation at the international level. As a result, there exist today a strong heterogeneity of regulatory positions with regard to ICOs. ${ }^{141}$

All in all - as the following summary shows - these cross-border differences and ongoing regulatory reforms suggest that ICO issuers, which now have to deal with more savvy and careful investors, should still follow a prudent approach and restrict their token sales to jurisdictions where an articulate and stable regulatory environment already exists. We provide below a synthetic overview of the various regulatory interventions that have been undertaken in different countries. ${ }^{142}$

\section{Summary of regulators' positions ${ }^{143}$}

- USA: The Howey test represents the fundamental test to ascertain whether a blockchain-based token qualifies as a security (ie as an investment contract). In July 2017, the SEC issued a statement holding that TheDAO tokens should be deemed as securities, because falling within the scope of the Howey test. It added that, in order to assess whether a token is a security, it is not enough to look at the utility model of the token, but one needs also look at the specific circumstances of each token sale. In December 2017, SEC Chairman Jay Clayton issued a public statement on cryptocurrencies and ICOs, stressing that the interpretation of securities law must focus on "substance over form". Hence, the fact that a token is a "utility token" does not necessarily precludes it from qualifying also as a security. One must look, in particular, at the marketing efforts of the team(s) promoting the ICO to see whether they are selling them to investors with an expectation of profits based on the entrepreneurial or managerial efforts of others - one of the hallmarks of a security under US law. This public statement came alongside a decision from the SEC holding that the token sale undertaken

141 For an overview of the various approaches to the regulation of ICOs in various jurisdictions, see eg Hacker and Thomale, supra, note 20; De Filippi et al, supra, note 70.

142 Please note that, as relevant laws and regulations may evolve quickly over time, some of the regulatory positions described at the time of writing might eventually become obsolete.

143 A general overview of the regulatory responses to ICOs in 25 jurisdictions can also be found in W Kaal, "Initial Coin Offerings: The top 25 jurisdictions and their comparative regulatory responses" (2018). A more in-depth analysis of the regulatory framework for ICOs in several jurisdictions can be found in De Filippi et al, supra, note 70. 
by Munchee was in violation of securities law. According to the SEC, "even if MUN tokens had a practical use at the time of the offering, it would not preclude the token from being a security". In particular, SEC underlined the fact that Munchee had promoted the ICO as a speculative investment and advertised it mostly in channels geared toward Bitcoin and Ethereum investors, rather than to the actual or potential users of the platform. In November 2018, the SEC released an enforcement report, ${ }^{144}$ revealing dozens of enforcement actions against a variety of token issuers, most of which had to pay penalties for failing to register their ICO as a security offering. Two of them (Airfox and Paragon) even agreed to refund the investors and register their tokens as securities. The SEC also brought charges against the founder of a decentralised exchange (EtherDelta) who was fined for running an unregistered securities exchange. Thus far, instead of enacting new laws or issuing informal guidance, the SEC is said to have adopted a "guidance by enforcement" approach, going after the easy targets in each relevant segment of the blockchain space, in order to establish a precedent that will inform the operations of similar initiatives.

- Singapore: The Monetary Authority of Singapore (MAS) issued a guidance in August 2017, a few days after the SEC's report on TheDAO, stipulating that certain tokens should be classified as financial securities under the Securities and Futures Act and should therefore be subject to the same regulatory requirements as traditional securities. It noted that a trading platform facilitating a secondary market for digital tokens might also need to be approved or recognised by the MAS as an approved exchange or recognised market operator, unless otherwise exempted. On November 2017, the MAS released a guide to Digital Token Offerings, delineating the regulatory framework that is currently in place and how it might affect an ICO. The Guide showed that the MAS is open to these new fundraising practises but will nonetheless exert its regulatory authority if ICOs are done in violation of existing laws. It also underlined that, even in the case of an ICO that is not subject to security laws, anti-money laundering and counter-terrorism financing regulations may still apply. The risk of investing in cryptocurrency and ICOs were reiterated in a statement of February 2018, ${ }^{145}$ where the MAS said that it will monitor ICOs more vigilantly, in order to report any violation to the relevant authorities.

- UK: The UK Financial Conduct Authority (FCA) joined the SEC and the MAS with a statement issued on 12 September 2017, warning investors of the risks inherent in ICOs. The FCA stated that, while some ICO tokens might qualify as investment products depending on the rights and expectations they provide to token holders, whether or not they qualify as securities is a question that must be assessed on a case-bycase basis. Hence, while some ICOs might fall within the scope of FCA regulations, it is unlikely that the FCA will regulate all ICOs, especially if they are based overseas. However, the FCA also indicated, in a statement from April 2018, ${ }^{146}$ that any firm offering cryptocurrency derivatives would require an express authorisation.

- Canada: The CSA Notice 46-307 (issued on 24 August 2017) discusses the applicability of Canadian securities laws to ICO. It first highlights that, thus far, most of the ICOs that the CSA has been consulted with qualify as the sale of securities, and should therefore be subject to the prospectus requirement, or file for an exemption. The notice also stipulates, however, that each ICO is unique and must be assessed on a case-by-case basis: while some tokens could be considered as financial securities, securities laws will not necessarily apply to all of them. It also specifies that, even if they do not qualify as securities, some of these tokens could, in certain cases, be considered as securities derivatives. Finally, recognising that the existing regulatory framework might not be appropriate for these new investment practices, the CSA encourages businesses to rely on the CSA Regulatory Sandbox to obtain temporary exemptive relief from securities law requirements. On September 2017, the Administrative Financial Markets Court, under a request from Quebec's Autorité des Marchés Financiers, held that the team behind the PlexCorp ICO was engaging in an unregistered security offering. As the team continued to solicit investors for their token sale, the Superior Court of Quebec found them guilty for contempt of court and sentenced them to jail. Conversely, on October 2017, the Ontario Securities Commission approved the ICO of Token Funder, demonstrating its willingness to play with ICO issuers that are willing to abide by the rules. While no law

144 US Securities and Exchange Commission, “Annual Report 2018, Division of Enforcement”, available at <www. sec.gov/files/enforcement-annual-report-2018.pdf>.

AQ5 145 Monetary Agency of Singapore, "Reply to Parliamentary Question on banning the trading of bitcoin currency or cryptocurrency" (2018), available at <www.mas.gov.sg/News-and-Publications/Parliamentary-Replies/2018/Reply-toParliamentary-Question-on-banning-the-trading-of-bitcoin-currency-or-cryptocurrency.aspx $>$.

146 See <www.fca.org.uk/news/statements/cryptocurrency-derivatives $>$. 
has been enacted in this regard, the OSC's 2018 Statement of Priorities ${ }^{147}$ indicates the regulation of ICO and similar offerings as an important priority in the coming years.

- Israel: Currently, token sales are not regulated in Israel under any body of law. However, the Israel Securities Authority (ISA) announced in late August 2017 that it will put into place a national committee to rule on whether tokens should be considered financial securities and to recommend a regulatory policy for ICOs. Thus far, the committee has taken a favourable position for ICOs with a view to becoming an "ICO hub". In March 2018, the Committee declared that Bitcoin would not be regarded as a security.

- China: The central bank of China issued a notice ${ }^{148}$ in September 2017 stating that ICOs were responsible for seriously disrupting the economic and financial order of the country and should be strictly forbidden. Token issuers are obliged to return all money raised through an ICO back to the investors. A further notice was issued to all China-based digital tokens exchanges, which were required to stop their operations. China prohibited the trading of cryptocurrency and the conversion from legal tender into cryptocurrencies, or vice versa. As of today, the government has stopped any ICO activity in mainland China and is expected to start blocking any website and online platform related to the trading of cryptocurrency or ICO tokens. ${ }^{149}$

- Hong Kong: The Securities and Future Commissions (SFC) of Hong Kong released a notice on September 2017, essentially reiterating the same findings as Singapore's MAS. It stated that the sale of digital tokens falling under the definition of securities might constitute a regulated activity and should therefore be licensed or registered with the SFC. In February 2018, the SFC released an announcement ${ }^{150}$ disclosing the various enforcement actions that it had taken against a series of token issuers, reminding exchanges that they should not trade tokens that qualify as securities without a licence to do so. A recent speech ${ }^{151}$ from the head of the SFC, Julia Leung, warned investors that many of these token offerings are "dubious, if not downright frauds".

- Malaysia: The Security Commission of Malaysia issued a statement in September 2017 warning investors of the various risks posed by ICOs, and the high number of frauds that come along with them. Because these practices are currently unregulated, the Commission warned investors about carrying out due diligence on the issuers and their operations. In December 2018, the Securities Commission of Malaysia issued a statement, ${ }^{152}$ describing its plans for early 2019 to regulate the issuance of digital tokens via ICOs and the trading of these tokens on exchanges, with a view to bring both activities under the umbrella of securities laws in order to ensure investor protection.

- South Korea: The Financial Services Commission (FSC) of South Korea created a working group in September 2017 aimed at exploring ways to improve KYC and combat terrorism financing. On 29 September 2017, the FSC declared all ICOs to be illegal on the ground that there are an increasing number of fraudulent ICOs being launched in the country. In May 2018, South Korea's National Assembly released a proposal to lift the ban, which has yet to be approved. In August 2018, the governor of Jeju Island proposed to make the island a "special zone" where token offerings would not be prohibited. In spite of these calls to legalise ICOs, the chairman of FSC has retained a firm position on the ban.

- Switzerland: For several years, the Swiss government has deliberately established a favourable regulatory environment for blockchain-related companies. Following the Ethereum crowdsale in 2014, the canton of Zug has attracted lots of ICOs, with many teams setting up a foundation as the legal vehicle to issue tokens and manage the raised funds. Yet, given the recent boom of ICOs incorporated in Switzerland, the FINMA has recently made an announcement, in September 2017, stating that various ICOs are currently

147 See <www.osc.gov.on.ca/documents/en/Securities-Category 1/sn_20180329_11-780_rfc-sop-end-2019.pdf >

148 PBOC, CAC, MIIT, SAIC, CBRC, CSRC, and CIRC, "Announcement on Preventing Financial Risks from Initial Coin Offerings" (4 September 2017), available at <www.pbc.gov.cn/goutongjiaoliu/113456/113469/3374222/index. html> (in Chinese).

149 Y Xie, "China to Stamp Out Cryptocurrency Trading Completely with Ban on Foreign Platforms", South China Morning Post (7 February 2018), available at <www.scmp.com/business/banking-finance/article/2132009/chinastamp-out-cryptocurrency-trading-completely-ban $>$.

150 See <www.sfc.hk/edistributionWeb/gateway/EN/news-and-announcements/news/corporate-news/doc? refNo $=18$ PR $13>$.

151 See $<$ www.sfc.hk/web/EN/files/ER/PDF/Speeches/Julia_20180413.pdf>.

152 See $<$ www.bnm.gov.my/index.php?ch $=$ en_press\&pg $=$ en_press\&ac $=4783 \&$ lang $=$ en $>$. 
being investigated for regulatory compliance, and that enforcement actions should be brought against the projects in violation of financial market regulations. Guide 04/2017, released in the same month, expressly specifies that, depending on their structure, many ICOs should be regulated under existing bodies of law, including money laundering, banking, securities and collective investment laws On February 2018, the FINMA has published a new set of guidelines describing how it intends to apply financial market regulations to ICOs. The FINMA distinguishes between: (a) payment tokens, which are not treated as securities but must comply with anti-money laundering regulations; (b) utility tokens that provide access to a particular application or service, which do not qualify as securities only if they are already functional at the point of issue, but only provided that there are no additional features that have an investment purpose; (c) asset tokens that represent participations in physical assets, companies or other revenue streams, and which clearly qualify as securities under Swiss law.

- Estonia: In November 2017, the Estonian Financial Sector Authority (EFSA) issued a statement on the regulatory framework of ICOs, stating that - depending on their nature and functions - tokens issued through an ICO might be regarded as securities. The EFSA reiterated the opinion of the SEC's Chairman, stipulating that, in assessing the legal qualification of these tokens, one should always consider "substance over form". Estonia is the first country that is considering launching its own ICO (Estcoin), an investment token that would be accessible to all e-Residents. Yet, while Estonia has shown itself to be quite open to these new fundraising practices, as an EU member state, it is unlikely that Estonia will be able to implement ad hoc legislation without a broader European consensus.

- France: In October 2017, the French Financial Markets Authority (AMF) published a public consultation on the application of existing regulatory framework to ICOs, and potential regulatory reforms to better accommodate these new fundraising practices. It provided three regulatory options for discussion: (1) maintaining the regulatory framework, whose scope is generally too narrow to encompass ICOs; (2) expanding the existing prospectus requirements to ICOs; (3) adopting (a) a mandatory; or (b) an optional registration and authorisation regime applicable to all ICOs in France, which would be more lightweight than the existing prospectus requirements. In the meantime, France has set up the Universal Node to ICO Research \& Network (UNICORN) with a view to exploring possible ways to reform the existing regulatory framework. More recently, France has taken steps to provide an actual regulatory framework for ICOs within its national jurisdiction. The Business Growth and Transformation bill ${ }^{153}$ (loi PACTE) that is currently being discussed is intended to promote innovation in the French economy. The bill comprises a whole section dedicated to ICOs (Art 26), stipulating that the issuers of security tokens will be subject to the standard regulation of security offering, whereas the issuers of tokens that do not qualify as security could be granted a licence from the AMF insofar as they comply with specific criteria. ${ }^{154}$ While obtaining a licence is not mandatory for the latter type of token, it is intended to provide visibility and greater legitimacy to the token offering.

- Germany: German national laws comprises a very narrow definition of what might qualify as a security, bringing most ICOs outside of the scope of German security laws. Other laws may apply, such as the Banking Act, Investment Code, Payment Service Supervision Act and the Insurance Supervision Act. It noted, however, that in order for German law to apply, the ICO must be specifically marketed to the German population. In November 2017, the German Federal Financial Supervisory Authority (BaFin) issued a statement warning investors of the potential risks involved with ICOs. In December 2017, the BaFin also published a translation of the European Securities Markets Authority (ESMA) publications concerning the risks to ICO issuers and investors.

- Italy: In December 2017, the Italian Security Commission (CONSOB) issued a warning, summarising the ESMA warnings regarding ICO issuers and investors. The warning was followed by two decisions. One was a resolution by the CONSOB concerning the trading platform CryptTrade, whose sale of “cryptocurrencies' extraction kits" preloaded with a fixed amount of cryptocurrency was held to constitute an offer to the public of a financial product that is subject to the prospectus requirements. The other was a decision by the Italian Antitrust Authority, which suspended the activities and fined the companies involved in the promotion of the Onecoin cryptocurrency, which was considered to fall under the category of a Ponzi scheme.

153 See <www.assemblee-nationale.fr/15/projets/pl1088.asp $>$.

154 Note that this solution is akin to option 3(b) from the public consultation. 
- Gibraltar: As a leading offshore financial centre, Gibraltar is opening up to cryptocurrency and ICOs as an attempt to position itself a crypto-hub. According to the Gibraltar Financial Service Commission (GFSC), tokens issued through an ICO will only be regarded as securities if they represent a share in a company. Hence, most ICOs thus far fall outside of security laws because tokens do not represent equity in a company. After issuing a preliminary consultation in January 2016, the government of Gibraltar has announced that it is considering putting in place regulations for the transfer of cryptocurrencies, and is exploring ways to accommodate blockchain-related companies, including those engaging in ICOs, within a more favourable regulatory framework. In March 2018, the Gibraltar Government released a white paper on token regulation ${ }^{155}$ describing how the government intends to regulate the promotion, sale and distribution of tokens, as well as the secondary market operators. The document reinstates the fact that most tokens will not qualify as securities under the law, but rather should be regarded as commercial products. The document highlights, however, that every token issuer might be required to appoint an "authorised sponsor" responsible to ensure that the token sale is done in compliance with disclosure and financial crimes laws. Specific regulations are expected to follow in early 2019.

- Liechtenstein: In September 2017, the Financial Market Authority of Lichtenstein published a fact sheet on ICOs, stating that the application of securities laws will depend on specific rights attached to the tokens issued through an ICO. The country also established a fast track fintech department in charge of responding to specific inquiries concerning the regulation of ICOs.

- Russia: In September 2017, the Central Bank of Russia issued a warning about the risks posed by cryptocurrencies and ICOs. In October 2017, President Putin issued a statement ordering the government and the central bank to develop a regulatory framework for the regulation of cryptocurrencies and ICOs. The Russian Ministry of Finance has been leading the drafting of a new bill on "digital financial assets", whereas the Russian central bank has been in charge of drafting the regulation alternative methods of fundraising, which specifically touches on crowdfunding and ICOs. The current version of this new regulatory framework stipulates that cryptocurrencies and tokens are to be regulated as financial assets, whose trading can only be achieved on authorised exchanges. It also imposes stringent KYC requirements for token issuances, and a limitation on the amount of funds that each individual can invest into an ICO. Because of disagreement between the Ministry of Finance and the Russian central bank as to the best way to regulate ICOs, the passing of these bills has been delayed. 